\title{
Size-dependent particle activation properties in fog during the ParisFog 2012/13 field campaign
}

\author{
E. Hammer ${ }^{1}$, M. Gysel ${ }^{1}$, G. C. Roberts ${ }^{2,3}$, T. Elias $^{4}$, J. Hofer ${ }^{1, * *}$, C. R. Hoyle ${ }^{1,5}$, N. Bukowiecki ${ }^{1}$, J.-C. Dupont ${ }^{6}$, \\ F. Burnet ${ }^{2}$, U. Baltensperger ${ }^{1}$, and E. Weingartner ${ }^{1, *}$ \\ ${ }^{1}$ Laboratory of Atmospheric Chemistry, Paul Scherrer Institute, 5232 Villigen PSI, Switzerland \\ ${ }^{2}$ CNRM/GAME - Meteo-France/CNRS, 42 av. Gaspard Coriolis, 31057 Toulouse, France \\ ${ }^{3}$ Scripps Institution of Oceanography, 9500 Gilman Dr., La Jolla CA 92093, USA \\ ${ }^{4}$ Hygeos, 165 Avenue de Bretagne, 59000 Lille, France \\ ${ }^{5}$ Swiss Federal Institute for Forest Snow and Landscape Research (WSL)-Institute for Snow and Avalanche Research (SLF), \\ 7270 Davos, Switzerland \\ ${ }^{6}$ Institut Pierre-Simon Laplace, Université Versailles Saint Quentin, 78280 Guyancourt, France \\ *now at: Institute for Aerosol and Sensor Technology, University of Applied Sciences, 5210 Windisch, Switzerland \\ ** now at: Leibniz Institute for Tropospheric Research (TROPOS), 04318 Leipzig, Germany
}

Correspondence to: M. Gysel (martin.gysel@psi.ch)

Received: 24 March 2014 - Published in Atmos. Chem. Phys. Discuss.: 8 April 2014

Revised: 5 September 2014 - Accepted: 8 September 2014 - Published: 7 October 2014

\begin{abstract}
Fog-induced visibility reduction is responsible for a variety of hazards in the transport sector. Therefore there is a large demand for an improved understanding of fog formation and thus improved forecasts. Improved fog forecasts require a better understanding of the numerous complex mechanisms during the fog life cycle. During winter 2012/13 a field campaign called ParisFog aiming at fog research took place at SIRTA (Instrumented Site for Atmospheric Remote Sensing Research). SIRTA is located about $20 \mathrm{~km}$ southwest of the Paris city center, France, in a semi-urban environment. In situ activation properties of the prevailing fog were investigated by measuring (1) total and interstitial (non-activated) dry particle number size distributions behind two different inlet systems; (2) interstitial hydrated aerosol and fog droplet size distributions at ambient conditions; and (3) cloud condensation nuclei $(\mathrm{CCN})$ number concentration at different supersaturations (SS) with a CCN counter. The aerosol particles were characterized regarding their hygroscopic properties, fog droplet activation behavior and contribution to light scattering for 17 developed fog events. Low particle hygroscopicity with an overall median of the hygroscopicity parameter, $\kappa$, of 0.14 was found, likely caused by substantial influence from local traffic and wood burning emissions. Measurements of the aerosol size distribution at ambient RH re-
\end{abstract}

vealed that the critical wet diameter, above which the hydrated aerosols activate to fog droplets, is rather large (with a median value of $2.6 \mu \mathrm{m}$ ) and is highly variable (ranging from 1 to $5 \mu \mathrm{m}$ ) between the different fog events. Thus, the number of activated fog droplets was very small and the nonactivated hydrated particles were found to contribute significantly to the observed light scattering and thus to the reduction in visibility. Combining all experimental data, the effective peak supersaturation, $\mathrm{SS}_{\text {peak }}$, a measure of the peak supersaturation during the fog formation, was determined. The median $\mathrm{SS}_{\text {peak }}$ value was estimated to be in the range from 0.031 to $0.046 \%$ (upper and lower limit estimations), which is in good agreement with previous experimental and modeling studies of fog.

\section{Introduction}

Aerosol hygroscopicity is defined as the ability of aerosol particles to take up water. This water uptake plays an important role in the Earth's radiative budget, as it changes the particle's light scattering and absorption properties. The interaction of aerosol with solar radiation can either be direct, or through the aerosol's modification of cloud properties. 
Aerosols influencing fog are also a major factor in visibility reduction at surface levels, which can cause fatalities in traffic (Rosenfeld, 1996). When the relative humidity increases, particles can grow substantially and if the atmosphere becomes supersaturated with respect to water vapor, particles can activate to form fog droplets (e.g., Bergot, 2007), depending on their size and hygroscopic properties. The term mist is used if visibility drops below $5 \mathrm{~km}$ (Vautard et al., 2009) and the term fog is used below a visibility threshold of $1 \mathrm{~km}$ (Tardif and Rasmussen, 2007; Maier et al., 2013). Studies in Europe showed that during developed fog, the visibility can decrease down to $50 \mathrm{~m}$ or lower (e.g., David et al., 2013; Elias et al., 2009).

In recent years, several field campaigns have been carried out in Europe and North America, focusing on physical and chemical processes in continental fog (Gultepe et al., 2007). Some studies investigated a certain fog type, such as radiation fog in the Fog-82 campaign in Albany, New York (Meyer et al., 1986), or radiation fog in the Lille- 88 and Lille-91 field experiments in northern France (Guedalia and Bergot, 1994). The role of turbulence in fog formation was studied at the Cabauw station in the Netherlands (Duynkerke, 1991). In the years 1989 and 1994, field campaigns were performed in the Po Valley, Italy (Heintzenberg, 1992), investigating fog microphysical processes (Noone et al., 1992b; Svenningsson et al., 1992) and the evolution of chemical species in the observed air masses (Facchini et al., 1992; Fuzzi et al., 1992). In the winter of $2006 / 2007$, the series of ParisFog field campaigns started to monitor important processes for fog formation and dynamics simultaneously (Haeffelin et al., 2010). This study presents results from the latest ParisFog campaign, which was conducted in the winter of 2012/2013.

Cloud condensation nuclei (CCN) activity can be defined by the particles' critical supersaturation ( $\left.\mathrm{SS}_{\text {crit }}\right)$, that is, the lowest supersaturation at which the particles can activate to a fog or cloud droplet. The critical supersaturation depends on the size and chemical composition of the particle (McFiggans et al., 2006). Cooling of an air parcel to temperatures below its dew point will result in the formation of a cloud or fog, and those particles with a critical supersaturation below the peak supersaturation in the cloud are activated to form cloud droplets. The effective peak supersaturation $\left(\mathrm{SS}_{\text {peak }}\right)$ of a cloud is defined as the highest supersaturation that a particle experiences for a sufficiently long time, such that all particles with $\mathrm{SS}_{\text {crit }}$ smaller than $\mathrm{SS}_{\text {peak }}$ are able to grow to a stable cloud/fog droplet (Hammer et al., 2014). The term effective is used here because very short supersaturation spikes that do not lead to additional droplet activation of particles are irrelevant in this context. $\mathrm{SS}_{\text {peak }}$ is a key parameter for aerosol-to-cloud droplet activation and is thus an important quantity for fog and cloud parametrizations in models (e.g., Kim and Yum, 2012; Stolaki et al., 2012; Zhao et al., 2012). Those particles having a larger critical supersaturation than the peak supersaturation of the air parcel will remain nonactivated in the hydrated aerosol mode. The largest size to which particles can grow while still being in stable equilibrium is at their $\mathrm{SS}_{\text {crit }}$, and is defined by the particle's size and hygroscopic properties (Petters and Kreidenweis, 2007). These unactivated particles, however, grow to their stable equilibrium size by taking up water and remaining smaller than activated droplets, but large enough to contribute significantly to extinction (sum of scattering and absorption) of visible radiation in fog (Elias et al., 2009).

Despite the advances in modeling (e.g., Bott et al., 1990; Stolaki et al., 2012), the representation of the physical processes leading to fog formation has not yet progressed to the point where numerical models can accurately forecast/nowcast fog events (Gultepe et al., 2007). The goals of this study are to examine the interaction between particles and fog, and the partitioning of water within this system to improve the understanding of fog formation.

A detailed examination of the aerosol properties during fog occurrence was performed to determine which fraction of the total particles is activated to fog droplets (Sect. 4.1). The activation properties of the particles within fog are further investigated by comparing dry with ambient (humid) size distribution measurements. The effective peak supersaturation is quantified and discussed for the fog events observed at the SIRTA site (Sect. 4.2). The contribution of hydrated but non-activated particles to the visibility reduction during fog is also investigated and the relative contribution of stable non-activated particles and activated particles to the light scattering is presented (Sect. 4.3).

\section{Experimental}

\subsection{ParisFog 2012/13 campaign}

ParisFog is a series of field campaigns focusing on fog research (Haeffelin et al., 2010). They have taken place at the Instrumented Site for Atmospheric Remote Sensing Research (SIRTA) several times since 2006. SIRTA is located in the immediate vicinity of the Ecole Polytechnique Palaiseau, on the Saclay plateau about $20 \mathrm{~km}$ southwest of the Paris city center. The site is located in a semi-urban environment composed of roughly equal portions of agricultural fields, wooded areas, housing and industrial developments (Haeffelin et al., 2005). SIRTA hosts active and passive remote sensing instruments to continuously quantify cloud and particle properties as well as key atmospheric parameters (Haeffelin et al., 2005). During the ParisFog 2012/13 campaign in the winter season (October to March), additional measurement instruments were provided and operated by several research institutes, as described below. During this time, the goal was to closely observe surface conditions, large- and small-scale dynamics, radiation, turbulence, precipitation, droplet-microphysics and particle-microphysics and particlechemistry. The data presented in this study cover the time period from 2 October 2012 to 7 January 2013. 


\subsection{Instrumentation}

The instrumentation used in this study is listed in Table 1. For the sampling of the particles and hydrometeors, a total and an interstitial inlet were installed on the roof of a measurement container at $4 \mathrm{~m}$ above ground level. The total inlet collected all particles (including droplets). The water associated with the hydrometeors and aerosol particles was evaporated by heating the top part of this inlet to approximately $20^{\circ} \mathrm{C}$, and subsequently all dried aerosol particles (non-activated aerosols and the residuals of the fog droplets) reached the instruments in the laboratory. The interstitial inlet sampled particles with an aerodynamic diameter smaller than $1 \mu \mathrm{m}$ at ambient relative humidity (RH; from 17 October 2012 07:00 to 14 November 2012 16:00 UTC). In the laboratory, the aerosol from both the interstitial and total inlets was dried to $\mathrm{RH}<20 \%$ as it was heated to room temperature (typically 20 to $30^{\circ} \mathrm{C}$ ). The maximum diameter of the sampled aerosol particles was increased to $2 \mu \mathrm{m}$ from 2 October 2012 17:00 to 17 October 2012 07:00 UTC and from 14 November 2012 16:00 to 7 January 2013 15:00 UTC. The cut-off diameter of the interstitial inlet was varied in order to test how the best separation between interstitial particles and activated fog droplets could be achieved. This inlet consists of an aerodynamic size discriminator $\left(\mathrm{PM}_{2.5}\right.$, Very Sharp Cut Cyclone, BGI, USA and $\mathrm{PM}_{1}$, Sharp Cut Cyclone 2.229, BGI Inc.) running at flow rates of $\sim 20 \mathrm{Lpm}\left(\mathrm{PM}_{2}\right)$ or $\sim 16 \mathrm{Lpm}$ $\left(\mathrm{PM}_{1}\right)$. The term interstitial is based on the assumption that all particles larger than the applied cut-off consist of activated cloud droplets. However, this was not always the case, particularly when the smaller cut-off diameter of $1 \mu \mathrm{m}$ was applied, as discussed in Sect. 4.2.

Inside the container, the dried number size distributions of total and interstitial particles were measured with a scanning mobility particle sizer (SMPS), consisting of a differential mobility analyzer (DMA; TSI 3071) and a condensation particle counter (TSI CPC 3022). The DMA was operated at a sample air flow rate of $0.3 \mathrm{Lpm}$ and a closed loop excess and sheath air set-up with a flow rate of $3 \mathrm{Lpm}$. The measured mobility diameters $\left(D_{\mathrm{mob}}\right)$ ranged from 13 to $520 \mathrm{~nm}$. The scan time of one size distribution was $6 \mathrm{~min}$, and after each scan the instrument was automatically switched between the total and interstitial inlets. The mean size distributions measured behind either inlet agreed well during fog-free periods, as both inlets deliver the total aerosol under these conditions. However, the total number concentration differed by up to $15 \%$ between consecutive scans due to temporal variability of the aerosol concentration. To minimize the effects of aerosol variability on the calculated activation curves, the total size distribution was compared with the average of the two interstitial size distributions measured immediately before and after.

To measure the cloud condensation nuclei $(\mathrm{CCN})$ number concentration, a miniature continuous flow streamwise thermal gradient $\mathrm{CCN}$ chamber (m-CCNC; Sullivan et al.,
2009) was installed downstream of the total inlet. This instrument was constructed at Scripps Institution of Oceanography based on the design of Roberts and Nenes (2005). The particles sampled behind the total inlet are introduced to the center of a column surrounded by a sheath of filtered humidified air. A linear temperature gradient along the column produces a well-defined and controlled supersaturation (SS) with respect to water. The SS is defined by the temperature gradient and the flow rate. Particles that take up water and grow to a diameter size of $>1 \mu \mathrm{m}$ are detected by an optical particle counter at the end of the column and are counted as CCN. The temperature differences and flow rate were scanned from 4 to $14 \mathrm{~K}$ and from 0.1 to $0.28 \mathrm{Lpm}$, respectively, such that a SS range of 0.05 to $0.6 \%$ was achieved (for the uncertainties, see Table 1). The m-CCNC was calibrated before and after the campaign using monodisperse ammonium sulfate particles (nebulized from a solution, dried by a diffusion drier and size-segregated by a DMA).

For the data analysis it is important to know when fog was present and especially how dense it was. For this task a Degreanne forward scatter sensor DF20+ was operated at a height of $3 \mathrm{~m}$ above the ground. The instrument provided a measurement of the horizontal visibility with a white light source (wavelength from 350 to $900 \mathrm{~nm}$ ) and a receiver placed off axis from the source. In addition, a Particle Volume Monitor (PVM-100; Gerber, 1991) additionally measured the liquid water content $\left(\mathrm{LWC}_{\mathrm{PVM}}\right)$ by forward light scattering.

An optical particle counter, WELAS 2000 (Palas Inc.), was used to measure the number size distribution of hydrated aerosol particles and fog droplets up to a diameter $\left(D_{\text {opt }}\right)$ of $\sim 10 \mu \mathrm{m}$ at ambient conditions by means of light scattering (size range between $360 \mathrm{~nm}$ and $42 \mu \mathrm{m}$ water droplet equivalent diameter). Droplets larger than $\sim 10 \mu \mathrm{m}$ could not be measured due to the inlet used with the WELAS 2000 (Burnet et al., 2012; Elias et al., 2014). The instrument was calibrated in the laboratory with monodisperse latex spheres (PSL; index of refraction $=1.59$ ). During fog events, when the $\mathrm{RH}$ is $\sim 100 \%$, the particles can be expected to be hydrated and mainly composed of water. Therefore, an index of refraction for water ( $m=1.333$ ) was used to infer correct particle/droplet sizes from the WELAS raw data. According to Heim et al. (2008), the detection efficiency is $\sim 1$ for $D_{\mathrm{PSL}} \gtrsim 1 \mu \mathrm{m}$, which translates into a water droplet diameter of $D_{\text {water }} \sim 1.4 \mu \mathrm{m}$. Thus, only WELAS data having a $D_{\text {water }} \gtrsim 1.4 \mu \mathrm{m}$ will be considered in this study.

\section{Methods}

\subsection{Classification of fog types}

According to Tardif and Rasmussen (2007), developed fog is defined by a visibility lower than $1.6 \mathrm{~km}$ (1 land mile; however, in Europe it is common to use a threshold of $1 \mathrm{~km}$; 
Table 1. Instrumentation deployed during ParisFog 2012/13 that provided data for this study.

\begin{tabular}{|c|c|c|c|c|}
\hline Measured parameter(s) & Instrument & Accuracy & Measurement range & Time resolution \\
\hline $\begin{array}{l}\text { Dry aerosol number size } \\
\text { distribution }\end{array}$ & $\begin{array}{l}\text { Scanning Mobility } \\
\text { Particle Sizer (SMPS) }\end{array}$ & $\begin{array}{l}\text { Number conc.: } \\
\pm 20 \%(20<D<520 \mathrm{~nm} ;) \\
\text { (Wiedensohler et al., 2012) }\end{array}$ & $D_{\mathrm{mob}}=13-520 \mathrm{~nm}$ & $6 \mathrm{~min}$ \\
\hline $\begin{array}{l}\text { Ambient aerosol and droplet } \\
\text { number size distribution }\end{array}$ & $\begin{array}{l}\text { Palas Welas-2000 } \\
\text { Particle Counter }\end{array}$ & $\begin{array}{l}\text { Number conc.: } \\
\pm 20 \% \\
\text { (Elias et al., 2009) }\end{array}$ & $\begin{array}{l}D_{\mathrm{opt}}=1.4-10 \mu \mathrm{m}^{*} \\
\text { (for water spheres) }\end{array}$ & $5 \mathrm{~min}$ \\
\hline $\begin{array}{l}\text { Cloud condensation nuclei } \\
(\mathrm{CCN}) \text { number concentration }\end{array}$ & $\begin{array}{l}\text { Continuous flow } \\
\text { streamwise thermal } \\
\text { gradient CCN } \\
\text { chamber } \\
\text { Degreanne DF20+ }\end{array}$ & $\begin{array}{l}\text { SS: } \pm 10 \% \\
\text { Number conc.: } \pm 10 \% \\
<5 \mathrm{~km}: \pm 10 \%\end{array}$ & $\mathrm{SS}=0.05-0.6 \%$ & $\begin{array}{l}1 \mathrm{~s} \\
(20 \mathrm{~min} / \\
\text { spectra })\end{array}$ \\
\hline Visibility & $\begin{array}{l}\text { forward scatter } \\
\text { sensor }\end{array}$ & $\begin{array}{l}5-20 \mathrm{~km}: \pm 15 \% \\
>20 \mathrm{~km}: \pm 25 \%\end{array}$ & $5 \mathrm{~m}-70 \mathrm{~km}$ & $1 \mathrm{~min}$ \\
\hline Liquid water content (LWCPVM) & $\begin{array}{l}\text { Particle Volume } \\
\text { Monitor (PVM-100) }\end{array}$ & $\begin{array}{l} \pm 15 \% \\
\text { (Allan et al., 2008) }\end{array}$ & $D=3-50 \mu \mathrm{m}$ & $1 \mathrm{~min}$ \\
\hline Temperature & PT-100 ATDM - MH13 & $\begin{array}{l} \pm 0.1 \mathrm{~K} \\
\text { (EdgeTech datasheet) }\end{array}$ & $-100-250^{\circ} \mathrm{C}$ & $1 \mathrm{~min}$ \\
\hline
\end{tabular}

*Size range with a detection efficiency of $\sim 1$. The full size range of the instrument is: $D=0.36-42 \mu \mathrm{m}$.

Haeffelin et al., 2010) for at least 30 min during a 50 min period. An automatic classification of fog events according to the scheme of Tardif and Rasmussen (2007) was carried out for the whole measurement period (2 October 2012 to 7 January 2013). The classification uses visibility, temperature, wind speed, precipitation, cloud cover and ceiling height as parameters to assign a type of fog to each event. The fog events were assigned to three different categories: (1) radiation fog (RAD) is mainly triggered by the balance of infrared radiative cooling and turbulent mixing, which cools the bottom air layer until it reaches saturation. Further radiative cooling at the top of the fog layer deepens it at the surface layer (Haeffelin et al., 2010). (2) Stratus lowering fog (STL) is initiated by a stratus cloud layer. Due to the radiative cooling at the cloud top, larger cloud droplets settle downwards to and beyond the cloud base, thus leading to a lowering of the cloud base (Dupont et al., 2012). (3) Precipitation fog (PREC), or in some literature also called frontal fog, is formed by rain that falls from warmer air masses down to colder air masses (subcloud layer) and evaporates. The corresponding evaporative cooling and additional water vapor leads to saturation and thus fog is able to form (Hupfer et al., 2005). However, precipitation fog occurred only once during the period covered in this study.

\section{$3.2 \kappa$-Köhler theory}

The equilibrium saturation vapor pressure $\left(\mathrm{RH}_{\mathrm{eq}}\right)$ over a solution droplet is described by the Köhler theory (Köhler, 1936) considering the Raoult (solute) and Kelvin effects. Petters and Kreidenweis (2007) introduced a simple parametrization for the solute (Raoult) term in the Köhler equation. With this, the semi-empirical " $\kappa$-Köhler equation" is obtained (here expressed for the equilibrium supersaturation $\mathrm{SS}_{\mathrm{eq}}$ as a function of the diameter of the solution droplet $D)$ :

$$
\begin{aligned}
& \operatorname{SS}_{\mathrm{eq}}(D):=\mathrm{RH}_{\mathrm{eq}}(D)-1 \\
& =\frac{D^{3}-\left(D^{\mathrm{dry}}\right)^{3}}{D^{3}-\left(D^{\mathrm{dry}}\right)^{3}(1-\kappa)} \exp \left(\frac{4 \sigma_{\mathrm{s} / \mathrm{a}} M_{\mathrm{w}}}{R T \rho_{\mathrm{w}} D}\right)-1,
\end{aligned}
$$

where $D^{\text {dry }}$ is the dry particle diameter, $\sigma_{\mathrm{s} / \mathrm{a}}$ is the surface tension of solution-air interface (in our calculations the surface tension of pure water was taken), $R$ is the universal gas constant, $M_{\mathrm{w}}$ is the molar mass of water, $T$ is the absolute temperature, $\rho_{\mathrm{w}}$ is the density of water and $\kappa$ is the hygroscopicity parameter, which depends on the particle chemical composition. Equation (1) provides the relationship between $\mathrm{SS}_{\mathrm{eq}}\left(\mathrm{RH}_{\mathrm{eq}}\right), D^{\text {dry }}, D$, and $\kappa$ under equilibrium conditions, and forms the basis for various theoretical calculations performed in the data analysis. For example, the critical supersaturation $\left(\mathrm{SS}_{\text {crit }}\right)$ of a particle with a certain dry size $\left(D^{\text {dry }}\right)$ and composition/hygroscopicity $(\kappa)$ is obtained by numerically searching for the maximum of Eq. (1) as a function of the droplet diameter $(D)$.

The hygroscopicity parameter $\kappa$, corresponding to a pair of $D^{\text {dry }}$ and $\mathrm{SS}_{\text {crit }}$, is obtained by numerically solving the $\mathrm{SS}_{\text {crit }}-D^{\mathrm{dry}}-\kappa$ relationship for $\kappa$. This is used to infer the $\kappa$ value from the CCNC and SMPS measurements, following the approach by Jurányi et al. (2011). 


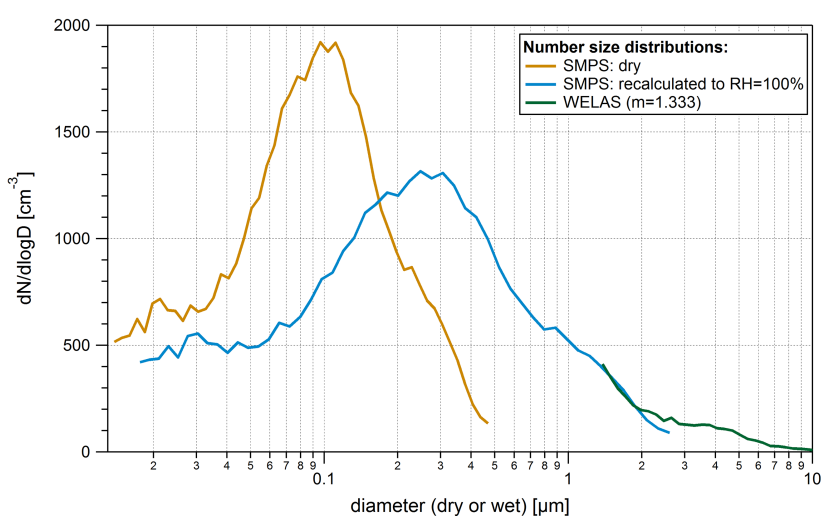

Figure 1. For the fog event F9 on 12 November 2012: median dry total aerosol dry number size distribution (brown) measured by the SMPS and corresponding ambient wet number size distribution (blue) recalculated to $\mathrm{RH}=100 \%$, assuming a hygroscopicity parameter $\kappa$ of 0.14 . The ambient aerosol and fog droplet number size distribution (green) was measured with a WELAS (using the refractive index of pure water, $m=1.333$, for the optical sizing).

\subsection{Reproducing the ambient total size distribution by combining dry SMPS with WELAS measurements}

Figure 1 shows, as an example, the median total dry number size distribution (in brown) for a stratus lowering fog event on 12 November 2012. Since the total inlet samples the interstitial as well as the activated particles and dries them, all particles, including droplet residuals, are measured with the SMPS. With the assumption that the ambient relative humidity $(\mathrm{RH})$ in the fog is approximately $100 \%$, the total dry size distribution measured by the SMPS (brown line in Fig. 1) was recalculated to the corresponding ambient wet size distribution assuming hydrated (non-activated) particles (blue line in Fig. 1) using $\kappa$-Köhler theory (Petters and Kreidenweis, 2007, see also Sect. 3.2) and a fixed $\kappa$ value of 0.14 (overall median $\kappa$ value discussed in Sect. 4.1). The recalculated SMPS size distribution is comparable to the WELAS measurement of the size distribution at ambient $\mathrm{RH}$ (see green line in Fig. 1) in the common size range of 1.4 to $2.6 \mu \mathrm{m}$, which is a strong indication that the majority of these particles are not activated, but hydrated particles in stable equilibrium. The total ambient size distribution for the complete diameter range of $17 \mathrm{~nm}$ to $\sim 10 \mu \mathrm{m}$ was obtained by merging the recalculated SMPS measurement with the WELAS measurement, whereby the recalculated SMPS measurements were taken up to a diameter of $1.4 \mu \mathrm{m}$ and the WELAS measurement covered the size range from $1.4 \mu \mathrm{m}$ to $10 \mu \mathrm{m}$.

\subsection{Retrieving the light scattering coefficients}

To investigate the influence of hydrated particles and fog droplets on the light scattering during the fog events, the light scattering coefficient size distribution $\left(\frac{\mathrm{d} b_{\mathrm{s}}}{\mathrm{d} \log D^{\text {wet }}}\right)$ was calculated from the ambient wet number size distribution $\frac{\mathrm{d} N^{\text {wet }}}{\operatorname{d} \log D^{\text {wet }}}$ :

$\frac{\mathrm{d} b_{s}\left(D^{\text {wet }}\right)}{\operatorname{d} \log D^{\text {wet }}}=\sigma\left(D^{\text {wet }}\right) \cdot \frac{\mathrm{d} N^{\text {wet }}\left(D^{\text {wet }}\right)}{\operatorname{d} \log D^{\text {wet }}}$,

where $\sigma\left(D^{\text {wet }}\right)$ is the scattering cross section for the solar spectrum (American Society for Testing and Materials (ASTM); www.astm.org/, last access: 6 November 2013) of a spherical water droplet with diameter $D^{\text {wet }}$ and a refractive index of $m=1.333-0 i$. The total light scattering coefficient, $b_{\mathrm{s}}$, is then obtained by integrating $\frac{\mathrm{d} b_{\mathrm{s}}}{\mathrm{d} \log D^{\mathrm{wet}}}$ over the whole diameter range.

\subsection{Retrieving the threshold wet diameter that separates activated droplets from non-activated hydrated particles}

Particles with a critical supersaturation above the effective peak supersaturation in the fog will remain in stable equilibrium, and their size remains restricted to their stable equilibrium diameter at the ambient $\mathrm{RH}(\sim 100 \%)$. Particles with a critical supersaturation below the effective peak supersaturation will be activated to droplets and keep growing until their water uptake pulls the ambient RH down to $100 \%$. This will lead to a size separation between the non-activated but hydrated particles and the activated fog droplets, given a sufficient amount of excess water vapor to substantially grow the fog droplets. The resulting minimum in the ambient number size distribution between the modes of the non-activated but hydrated particles and the activated fog droplets approximately represents the size of the particles at the activation threshold, hereafter referred to as $D_{\text {thres }}^{\text {wet }}$. For most fog events, no distinct minimum was detected in the number size distribution, most probably due to limited growth of the few activated fog droplets. Therefore the surface size distribution of the aerosol was instead used to determine $D_{\text {thres }}^{\text {wet }}$ (see Fig. 2). In practice, this was achieved by fitting a bimodal log-normal distribution to the wet surface size distribution, obtained by merging the SMPS and WELAS measurements (see Sect. 3.3). This approach of determining $D_{\text {thres }}^{\text {wet }}$ is essentially equivalent to the method by Elias et al. (2014), except that they used the volume size distribution, which results in slightly larger threshold diameters, as will be shown below.

The threshold diameter $D_{\text {thres }}^{\text {wet }}$, which represents the equilibrium diameter at $\mathrm{RH}=100 \%$, was then recalculated to the corresponding dry particle diameter using the $\kappa$-Köhler theory (Petters and Kreidenweis, 2007, see also Sect. 3.2) and a $\kappa$ value of 0.14 (this is the reverse calculation of what is described in Sect. 3.3). The threshold diameter $D_{\text {thres }}^{\text {wet }}$ is considered to be slightly biased high, due to the $D^{2}$ weighting of the surface size distribution, and thus the corresponding dry size is considered to represent an upper estimate for the dry activation threshold diameter $D_{\text {act }}^{\text {upper }}$. 


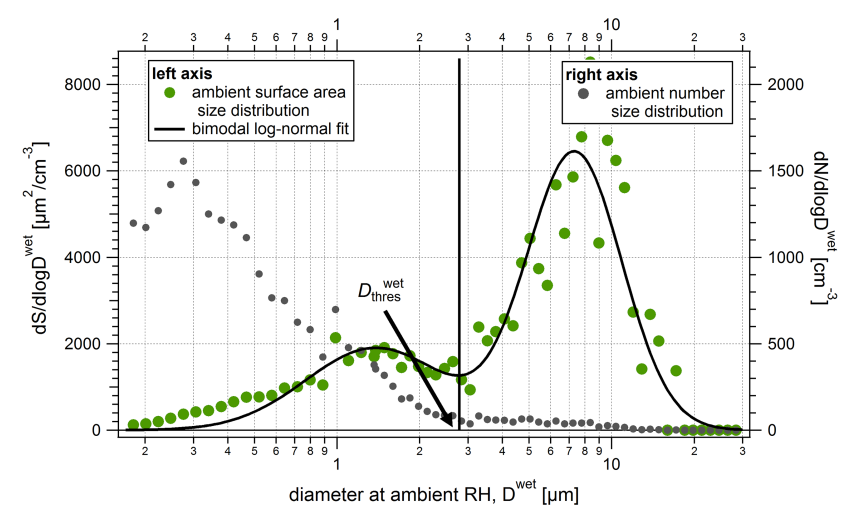

Figure 2. For the fog event F9 on 12 November 2012 04:45: 12 min average number and surface area size distribution at ambient RH from the merged SMPS (recalculated to RH of $100 \%$ ) and WELAS measurement. A bimodal log-normal fit of the scattering coefficient was used to retrieve the $D_{\text {thres }}^{\text {wet }}$.

\subsection{Retrieving the dry activation diameter from the interstitial and total particle size distributions}

In the presence of a cloud, the dry activation threshold diameter $\left(D_{\text {act }}\right)$ can be experimentally determined from the measured dry interstitial and total number size distributions via calculating the activated fraction (AF) of the dry particles with a diameter $D^{\text {dry }}$ (see Fig. 3). AF was calculated as follows (Verheggen et al., 2007):

$$
\operatorname{AF}\left(D^{\mathrm{dry}}\right)=\frac{\frac{\mathrm{d} N_{\text {tot }}}{\mathrm{d} \log D^{\mathrm{dry}}}\left(D^{\mathrm{dry}}\right)-\frac{\mathrm{d} N_{\text {int }}}{\operatorname{dlog} D^{\mathrm{dry}}}\left(D^{\mathrm{dry}}\right)}{\frac{\mathrm{d} N_{\text {tot }}}{\operatorname{d} \log D^{\mathrm{dry}}}\left(D^{\mathrm{dry}}\right)},
$$

where $\frac{\mathrm{d} N_{x}}{\operatorname{dog} D^{\mathrm{dry}}}\left(D^{\mathrm{dry}}\right)$ is the value of the number size distribution at diameter $D^{\text {dry }}$ and behind inlet $x$. The diameter, $D_{\text {act }}^{\text {lower }}$, at which $50 \%$ of the particles of this size were activated, i.e., $\operatorname{AF}\left(D_{\text {act }}^{\text {lower }}\right)=0.5$, provides a lower estimate for the dry activation diameter in the observed fog. It is a lower estimate for the true activation diameter, because the largest non-activated particles were sometimes also removed by the interstitial inlet for the set-up applied in this study, as further discussed in Sect. 4.2.

\subsection{Retrieval of the effective peak supersaturation and associated uncertainties}

Combining $D_{\text {act }}$ with the particle hygroscopicity, obtained from the simultaneous CCNC measurements, makes it possible to infer the effective peak supersaturation of the cloud

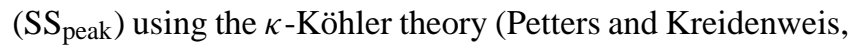
2007). A detailed description of this procedure can be found in Hammer et al. (2014).

The measured $D_{\text {act }}$ and $\kappa$ are used as input for Eq. (1) to infer the effective peak supersaturation. Thereby it is assumed that the activation occurred at the same temperature

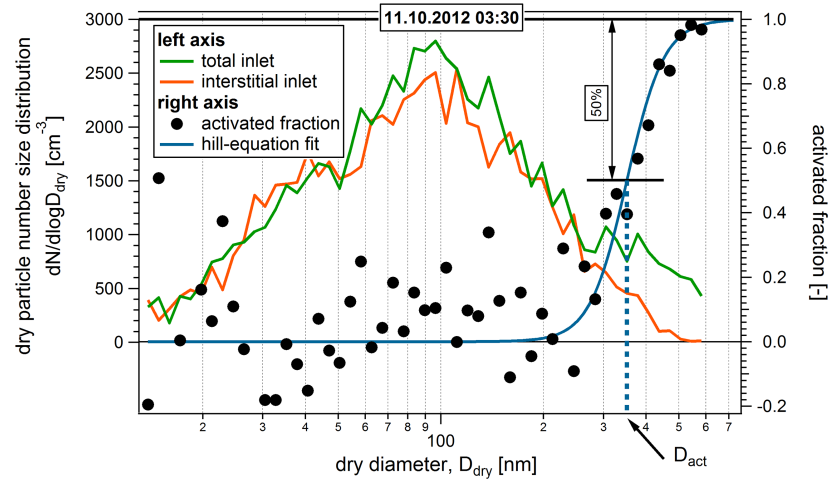

Figure 3. $12 \mathrm{~min}$ average aerosol number size distributions measured behind the total (green) and interstitial (red) inlet for a developed fog event. The right axis shows the corresponding calculated activated fraction. The half-rise of the hill-equation fit (solid blue line) is defined as the dry activation diameter $\left(D_{\text {act }}^{\text {dry }}\right.$; indicated with the blue dashed line), where $50 \%$ of the particles were removed at the interstitial inlet because they grew above the cut-off of the impactor $(2 \mu \mathrm{m})$, either due to activation to a fog droplet or due to a stable equilibrium diameter in the fog $(\mathrm{RH} \approx 100 \%)$ above the impactor cut-off.

as measured $2 \mathrm{~m}$ above ground. The theoretical critical supersaturation corresponding to these values, which we define as $\mathrm{SS}_{\text {peak }}$ of the cloud, is then obtained with the $\kappa$-Köhler theory (Sect. 3.2).

Since two different methods for retrieving $D_{\text {act }}$ were addressed in Sects. 3.5 and 3.6, two different $\mathrm{SS}_{\text {peak }}$ were retrieved: using $D_{\text {act }}^{\text {upper }}$ and $D_{\text {act }}^{\text {lower }}$ provides a lower and upper estimate for $\mathrm{SS}_{\text {peak }}$, respectively (subsequently referred to as $\mathrm{SS}_{\text {peak }}^{\text {lower }}$ and $\left.\mathrm{SS}_{\text {peak }}^{\text {upper }}\right)$.

The experimental uncertainty for $S_{\text {peak }}^{\text {upper }}$ was estimated using the uncertainties described in Table 1 . The variability (25th/75th percentiles) of the $\kappa-D^{\text {dry }}$ relationship from the time-resolved $\mathrm{CCN}$ measurements and the uncertainty from the temperature sensor was used as an estimate for the uncertainty of $\kappa\left(D_{\text {act }}\right)$ (see Sect. 4.1 for further discussion). Applying these uncertainties for the retrieval of $\mathrm{SS}_{\text {peak }}$, a relative uncertainty of about $48 \%$ (i.e., ca. 1 standard deviation) was estimated for $\mathrm{SS}_{\text {peak }}^{\text {upper }}$.

The uncertainty of $\mathrm{SS}_{\text {peak }}^{\text {lower }}$ is dominated by the uncertainty of $D_{\text {thres }}^{\text {wet }}$ inferred from the WELAS measurement. The uncertainty of $D_{\text {thres }}^{\text {wet }}$ is estimated to be $\sim \pm 20 \%$ associated with finding the minimum in the size distribution (the sizing uncertainty of the WELAS is only $\sim \pm 9 \%$ according to Rosati et al., 2014). A relative uncertainty of $\pm 3 \%$ in $\mathrm{SS}_{\text {peak }}^{\text {lower }}$ arises from a temperature uncertainty of $\pm 10^{\circ} \mathrm{C}$. $\mathrm{SS}_{\text {peak }}^{\text {lower is virtu- }}$ ally independent of the $\kappa$ value used to infer it from $D_{\text {thres }}^{\text {wet }}$, because in this approach the $\kappa$-Köhler theory is just used to extrapolate the Köhler curve over a very small change in RH and droplet diameter. On the other hand, the inferred $D_{\text {act }}^{\text {upper }}$ would decrease by $\sim 20 \%$ if a $\kappa$ value of 0.3 was assumed 
instead of 0.14 . The propagated uncertainty of $\mathrm{SS}_{\text {peak }}^{\text {lower }}$ is dominated by the $\pm 20 \%$ partial uncertainty of $D_{\text {thres }}^{\text {wet }}$.

The RH in the developed fog will stabilize slightly above $100 \% \mathrm{RH}$, depending on the fog droplet sizes that are reached while buffering the excess water. The fact that the $\mathrm{RH}$ in the developed fog is not exactly known adds some un-

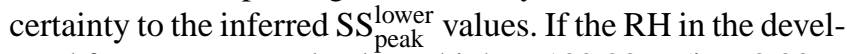
oped fog was assumed to be as high as $100.03 \%$ (i.e., $0.03 \%$ SS) instead of exactly $100.00 \%$, then the $\mathrm{SS}_{\text {peak }}^{\text {lower }}$ would increase by $17 \%$ (relatively). In the interest of providing a conservative estimate for $\mathrm{SS}_{\text {peak }}^{\text {lower }}$, we assume an RH of exactly $100 \%$ for this approach.

\section{Results and discussion}

During the ParisFog 2012/13 campaign, 17 developed fog events were detected at the SIRTA site. Table 2 lists all fog events with the corresponding fog type, cut-off diameter at the interstitial inlet and median liquid water content (LWC) measured by the PVM (LWC $\mathrm{PVM}_{\mathrm{PVM}}$ ). The next nine columns show the median effective peak supersaturations $\left(\mathrm{SS}_{\text {peak }}\right.$; lower and upper estimate), median dry activation diameter ( $D_{\text {act }}$; lower and upper estimate), median threshold diameter ( $D_{\text {thres }}^{\text {wet }}$ ), the scattering coefficients for the modes of hydrated particles $\left(b_{\mathrm{s}, \text { hyd }}\right)$ and the activated droplets up to a diameter of $10 \mu \mathrm{m}\left(b_{\mathrm{s}}\right.$, drop $)$, the fractional contribution of the nonactivated but hydrated particles to light scattering of $b_{\mathrm{s} \text {, hyd }}$ to $\left(b_{\mathrm{s}, \text { hyd }}+b_{\mathrm{s} \text {, drop }}\right)$, and particle extinction coefficient (pec) that are discussed in Sects. 4.2 and 4.3.

Seven fog events of the type STL and seven fog events of the type RAD were detected. One fog event of the type PREC was detected, however, neither the SMPS nor the WELAS measured the latter fog type, therefore no results are presented for this event.

Figure 4 gives an overview of the most important meteorological parameters, the fog presence and type (in different color bars), and the total particle number concentration during the campaign. The temperature slightly decreases from the beginning of the campaign towards the end with a minimum value of $-6^{\circ} \mathrm{C}$ and a maximum value of $23^{\circ} \mathrm{C}$ (Fig. 4a). The wind speed at the site was rather moderate during the whole campaign, ranging from 0 to $11.3 \mathrm{~m} \mathrm{~s}^{-1}$ (Fig. 4a). There is a high frequency of wind coming from the northeast and thus polluted air from the Paris metropolitan area is transported to the site (Haeffelin et al., 2005). In Fig. 4b, the total particle number concentration is depicted and reveals rather high pollution transported from Paris with northeastern wind direction. Maximum values of $12800 \mathrm{~cm}^{-3}$ and a median value of $2800 \mathrm{~cm}^{-3}$ in the total particle number concentration were encountered. However, the studies of Crippa et al. (2013a) found at the same site that a major part of the fine particulate matter in Paris is contributed by the regional background rather than by local pollution. Thus, the higher pollution with northeastern wind directions measured at the SIRTA site may be attributed to more continental influence compared to the cleaner western sector, but also to the local influence of road traffic and wood burning emissions (Crippa et al., 2013b, as will be further discussed in Sect. 4.1).

Figure $4 \mathrm{c}$ presents the visibility measured by the Degreanne forward scatter sensor DF20+ instrument on a log-scale with the threshold at $1 \mathrm{~km}$ (dotted line) defining developed fog. Events where the visibility decreased to values between 1 and $5 \mathrm{~km}$ are defined as mist or quasi-fog. Such events were investigated at the SIRTA in detail (Elias et al., 2009; Haeffelin et al., 2013). Median visibility ranges of $244 \mathrm{~m}$ and $211 \mathrm{~m}$ were observed for developed RAD and STL fogs during ParisFog 2012/13, respectively, reaching down to a minimum of $107 \mathrm{~m}$ ( $1 \mathrm{~h}$ average). In earlier campaigns minimum values down to $\sim 50 \mathrm{~m}$ were observed at the SIRTA site (Haeffelin et al., 2010).

\subsection{Particle hygroscopic properties during ParisFog 2012/13}

The hygroscopicity of aerosol particles is relevant for many atmospheric processes; it can be described with the hygroscopicity parameter $\kappa$ (Sect. 3.2), which is required in this study to infer the $\mathrm{SS}_{\text {peak }}$ from the observed activation diameters. The hygroscopicity parameter as a function of particle dry size, $\kappa\left(D^{\text {dry }}\right)$, was determined from simultaneous total polydisperse $\mathrm{CCN}$ number concentration and aerosol size distribution measurements, following the approach described in Jurányi et al. (2011) and Hammer et al. (2014). While total aerosol size distributions are available for the whole period, there are some gaps of the measurement period for the $\mathrm{CCN}$ measurements. Therefore, median data of $\kappa\left(D_{\text {act,CCNC }}\right)$ were used to infer $\mathrm{SS}_{\text {peak }}$ for all the fog events of ParisFog 2012/13.

Figure 5 shows the median $\kappa$ values observed during ParisFog 2012/13. The median $\kappa$ value decreased from 0.17 at $D_{\text {dry }}=69 \mathrm{~nm}$ to 0.09 at $D_{\text {dry }}=295 \mathrm{~nm}$ and then increased to 0.17 at $310 \mathrm{~nm}$. The abrupt change in $\kappa$ between 295 and $310 \mathrm{~nm}$ dry diameter is unreasonable and may be attributed to increased experimental uncertainty of CCN measurements at very low SS. In this study we have chosen a fixed $\kappa$ value of 0.14 , which represents a mean value across the size range from 205 to $330 \mathrm{~nm}$, for inferring $\mathrm{SS}_{\text {peak }}$ from $D_{\text {act }}$. The $\kappa$ values observed in this study are very close to the previously reported wintertime values for the same site (Jurányi et al., $2013 ; \kappa=0.08-0.24$ for $D_{\text {dry }}=50-177 \mathrm{~nm}$ ) as well as Paris city center (Kamilli et al., 2014); $\kappa=0.17$ for $D_{\text {dry }}=285 \mathrm{~nm}$ ). The $\kappa$ values reported for Paris are substantially lower than the observed and modeled average value of $\kappa \approx 0.3$ for continental sites (Andreae and Rosenfeld, 2008; Pringle et al., 2010). This low $\kappa$ value is most likely due to the influence of non- or less-hygroscopic road traffic and residential wood burning emission (Crippa et al., 2013b), which 


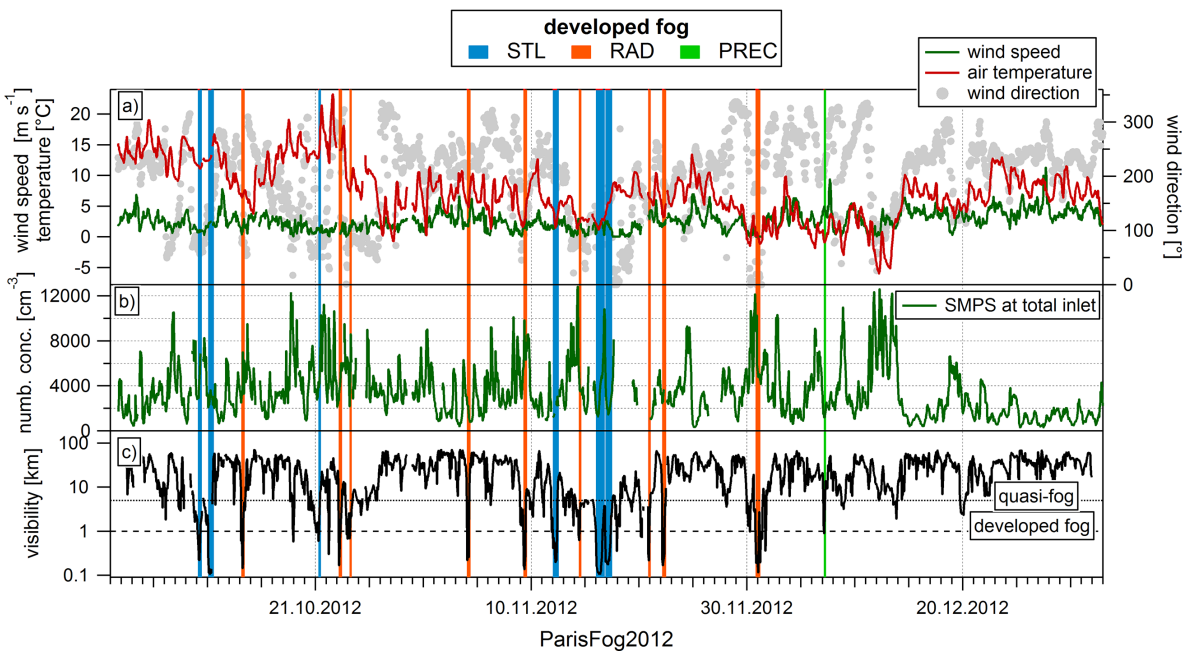

Figure 4. All detected fog events (stratus lowering fog; STL, radiation fog; RAD and precipitation fog; PREC) during ParisFog 2012/13 shown with wind speed, wind direction and air temperature (a), total particle number concentration (b) and visibility (c).

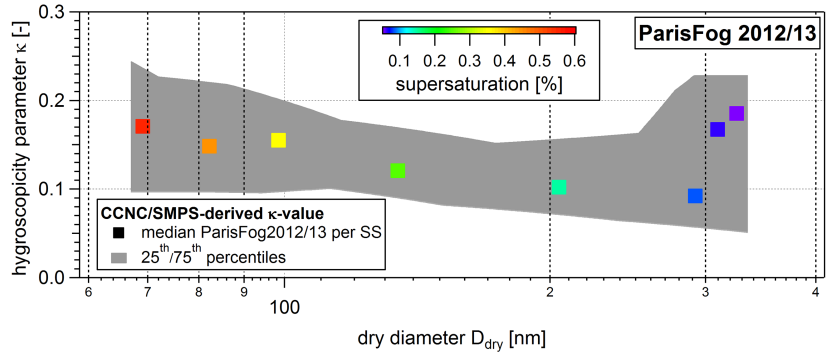

Figure 5. Hygroscopicity parameter $(\kappa)$ as a function of dry particle size during the ParisFog 2012/2013 campaign as derived from the polydisperse $\mathrm{CCN}$ and dry particle number size distribution measurements. The median values are given in color-coded markers after supersaturation, and the 25 th and 75 th percentiles are indicated with grey shading.

lowers the mean hygroscopicity of the aerosol substantially (Baltensperger et al., 2002; Laborde et al., 2013).

The variability in the $\kappa$ value over the whole period of ParisFog 2012/13 is indicated by the shaded area between the 25 th and 75 th percentiles of all data during the 3 months in Fig. 5. The variability in time in the values is fairly small, particularly between diameters of about 100 and $250 \mathrm{~nm}$. At larger particle diameters ( 250 to $350 \mathrm{~nm}$ ) the range between the 25th and 75th percentile increases somewhat. This low variability and the fact that $\mathrm{SS}_{\text {peak }}$ is insignificantly sensitive to $\kappa$, permit the use of averaged $\kappa$ values instead of timeresolved $\kappa$ values derived from simultaneous $\mathrm{CCN}$ measurements.

\subsection{Observed fog activation properties}

The droplet diameters observed during the events are in the range where very large and hygroscopic particles can exist in stable equilibrium. This brings up the question whether supersaturation and true droplet activation occurred at all during fog formation. We are confident that this was the case, as particles on the stable side of the Köhler curve, which have a clearly defined equilibrium diameter, cannot buffer the RH at $100 \%$ by uptake or release of water vapor if the ambient temperature varies. Thus, if the air cools below the temperature that corresponds to $100 \% \mathrm{RH}$, then the $\mathrm{RH}$ will exceed $100 \%$ and the peak supersaturation will only be reached when the activated droplets have taken up enough water to reduce the $\mathrm{RH}$ back to $100 \% \mathrm{RH}$.

For measuring the interstitial aerosol, a size cut-off of 1 or $2 \mu \mathrm{m}$ was used during the campaign (see Sect. 2.2). In another fog-campaign performed in the Po Valley, Italy, a size cut-off of $5 \mu \mathrm{m}$ was used to distinguish the interstitial from the activated particles (Noone et al., 1992a). Thus, it is important to know which ambient threshold diameter separates the activated fog droplets from the non-activated, but hydrated, particles. In non-fog cloud types, the cooling rates experienced by the air parcel are generally larger than in the case of fog. Therefore the activated droplets experience larger water fluxes, resulting in larger growth rates such that the two modes of hydrated aerosols and activated droplets are much more distinct in diameter for clouds (e.g., at the Jungfraujoch, Switzerland, Henning et al., 2002, or for marine stratus clouds, Baltic Sea, Ditas et al., 2012) than observed in fog, as we will see in the following.

Figure 6a shows the ambient aerosol number size distribution and Fig. $6 \mathrm{~b}$ the corresponding normalized surface size distribution for the fog event F7 detected on 4 November 2012. The aerosol size distribution at ambient RH was obtained by complementing the direct WELAS measurement (for diameters larger than $1.4 \mu \mathrm{m}$ ) with the SMPS measurement of the total aerosol dry size distribution recalculated to 


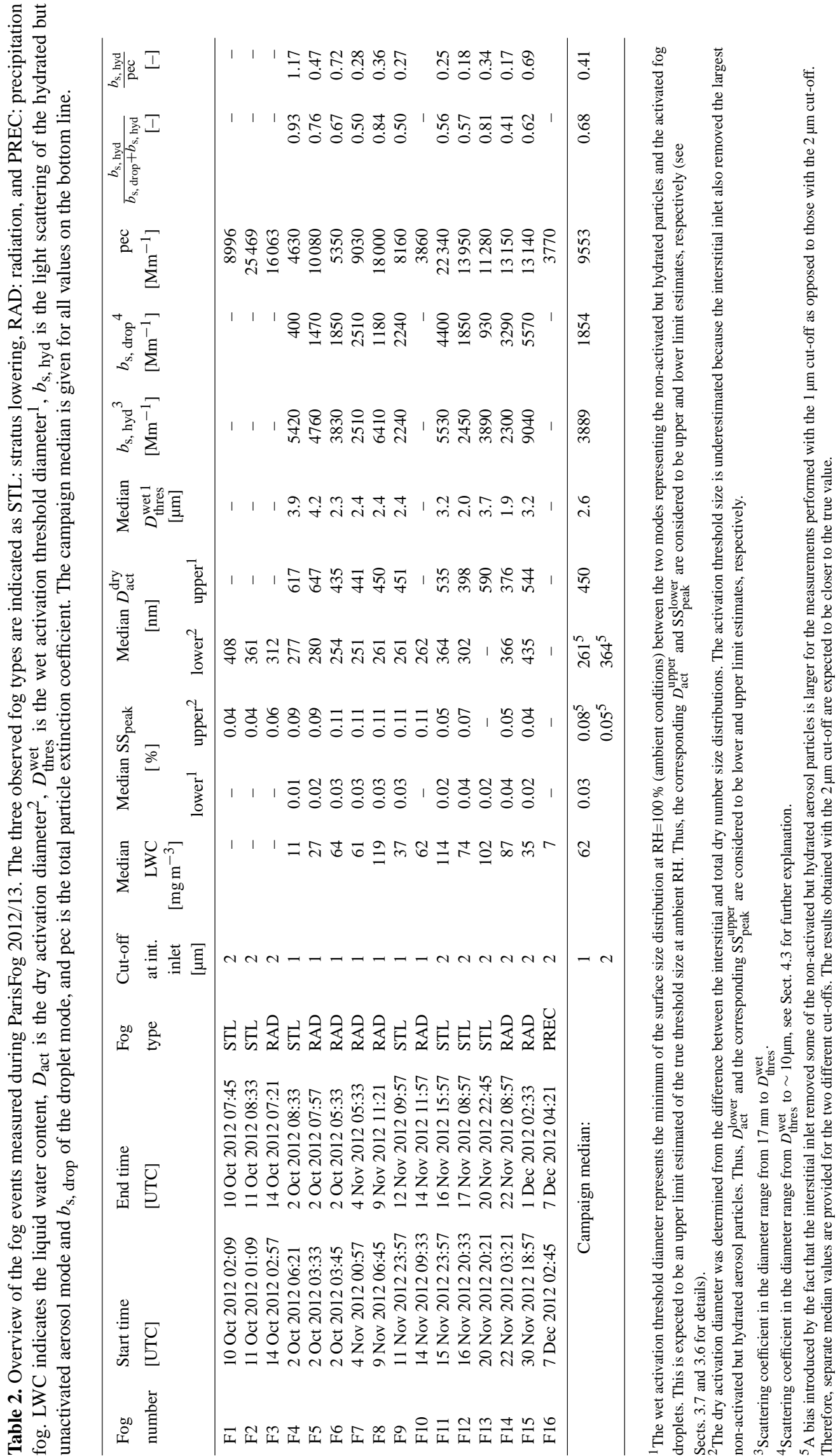




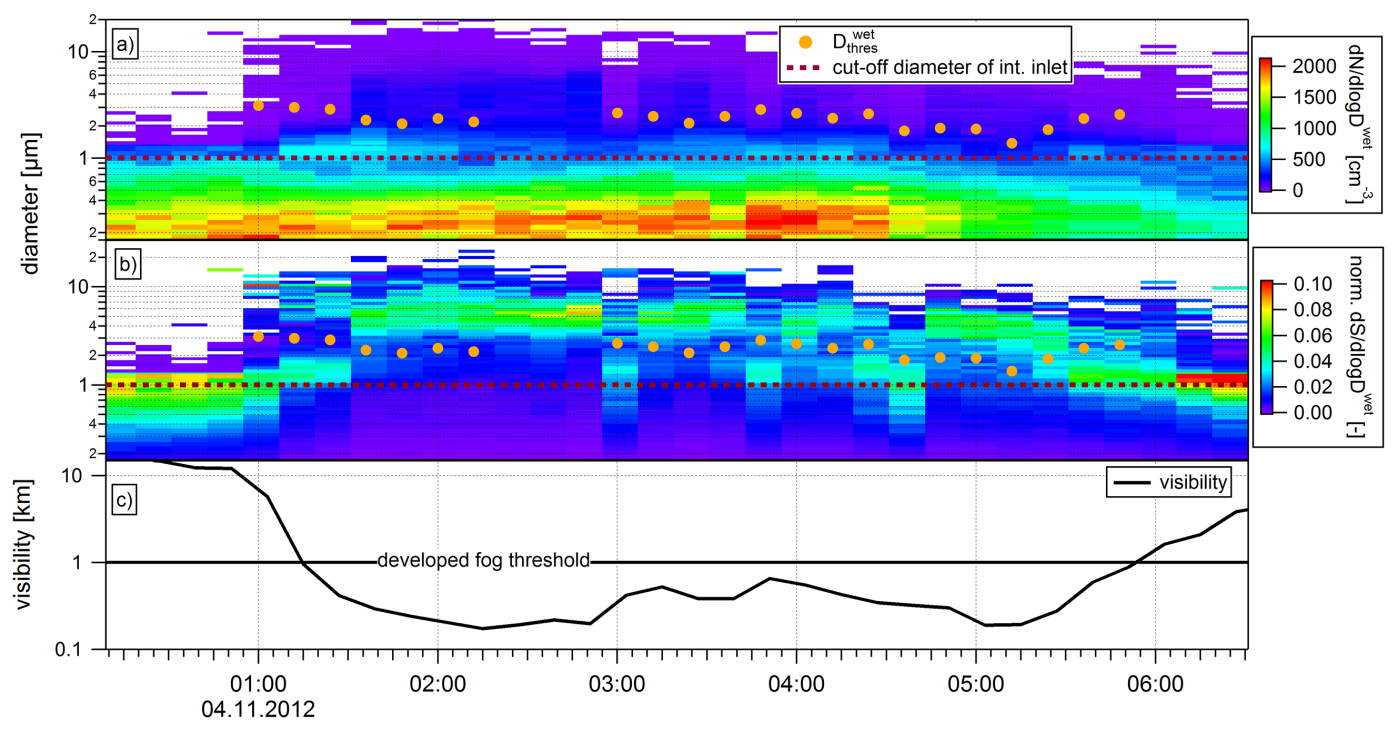

Figure 6. Radiation fog event F7 observed on 4 November 2012. Ambient number size distribution $\left(\frac{\mathrm{d} N}{\mathrm{~d} \log D^{\text {wet }}}\right)$ obtained by combining the WELAS measurement (for $D^{\text {wet }}>1.4 \mu \mathrm{m}$ ) merged with the SMPS measurement recalculated to RH=100\% (for $\left.D^{\text {wet }}<1.4 \mu \mathrm{m}\right)(\mathbf{a})$, the corresponding normalized ambient surface size distribution $\left(\frac{\mathrm{d} S}{\operatorname{dog} D^{\text {wet }}}\right)$, together with the wet activation threshold diameter (orange circles; $D_{\text {thres }}^{\text {wet }}$ ) and the cut-off diameter applied at the interstitial inlet (red dotted line) (b), and the visibility measured by the Degreanne DF20+ forward scatter sensor $(\mathbf{c})$.

$\mathrm{RH}=100 \%$ (for the diameter range smaller than $1.4 \mu \mathrm{m}$, as detailed in Sect. 3.3). Droplets with diameters larger than $2 \mu \mathrm{m}$ are only observed at times with developed fog, in other words, when the visibility is below the threshold value of $\sim 1 \mathrm{~km}$. This suggests that these large droplets represent activated fog droplets, while droplets with diameters $<\sim 2 \mu \mathrm{m}$ are non-activated but hydrated aerosol particles. The activated fog droplets appear as a distinct mode in the normalized surface size distribution (Fig. 6a). The minimum in the surface size distribution below the fog droplet mode, shown with orange markers in Fig. 6b, is considered to be an estimate of the threshold diameter, $D_{\text {thres }}^{\text {wet }}$, for fog droplet activation, as detailed in Sect. 3.5. It is important to note that large and very hygroscopic $\mathrm{CCN}$ with critical droplet diameters above $\sim 5 \mu \mathrm{m}$ may potentially remain in stable equilibrium, even under developed fog conditions, coexisting with smaller and/or less hygroscopic CCN that got truly activated (e.g., Phinney et al., 2003). The reason for this phenomenon are kinetic limitations (Nenes et al., 2001): depending on the conditions, the $\mathrm{CCN}$ with smaller critical wet diameter require less time to grow across their critical size, compared to the $\mathrm{CCN}$ with much larger critical diameter. However, this phenomenon does not invalidate the data analysis approach for retrieving the $D_{\text {thres }}^{\text {wet }}$, which uses the minimum in the droplet size distribution between the modes from unactivated droplets in stable equilibrium and truly activated droplets, because the large CCNs would show up in the uppermost tail of the droplet size distribution.

The cut-off diameter of $1 \mu \mathrm{m}$ applied at the interstitial inlet for the example in Fig. 6 is always clearly below the wet activation threshold diameter. Thus, a significant fraction of the non-activated but hydrated particles are removed from the interstitial inlet, in addition to the fog droplets, which are supposed to be removed. In those cases the dry activation diameter $\left(D_{\text {act }}\right)$, as explained in Sect. 3.6, reflects the dry size corresponding to the hydrated particles with an equilibrium size at ambient RH that is equal to the cut-off of the interstitial inlet. Thus, the inferred $D_{\text {act }}$ is a lower estimate for the dry activation threshold diameter and is called $D_{\text {act }}^{\text {lower }}$. The bias introduced by this artifact is the more significant the lower the cut-off of the interstitial inlet is. Thus, the results obtained from measurements with the $2 \mu \mathrm{m}$ cut-off are expected to be closer to the true value than those obtained with the $1 \mu \mathrm{m}$ cut-off. This is illustrated with the ambient aerosol number and surface size distributions observed during fog event F11 (Fig. 7a and b), when a $2 \mu$ m cut-off was applied at the interstitial inlet. In this case, the wet activation threshold diameter is closer to the inlet cut-off and thus the bias in the retrieved $D_{\text {act }}^{\text {lower }}$ is expected to be small.

Figure $7 \mathrm{c}$ shows the dry activation diameters $D_{\text {act }}^{\text {upper }}$ and $D_{\text {act }}^{\text {lower }}$ inferred from the wet activation threshold diameter and the interstitial/total dry size distribution measurements for fog event F11, respectively (see Sects. 3.5 and 3.6 for the methodology). The difference between $D_{\text {act }}^{\text {upper }}$ and $D_{\text {act }}^{\text {lower }}$ is small when the wet activation threshold diameter is around the cut-off of the interstitial inlet and larger at other times.

The estimate of $D_{\text {act }}$ combined with the particle hygroscopicity from CCN measurements are the basis to infer the effective peak supersaturation $\left(\mathrm{SS}_{\text {peak }}\right)$ of fog according to the methodology addressed in Sect. 3.7. A $\kappa$ value of 0.14 , 


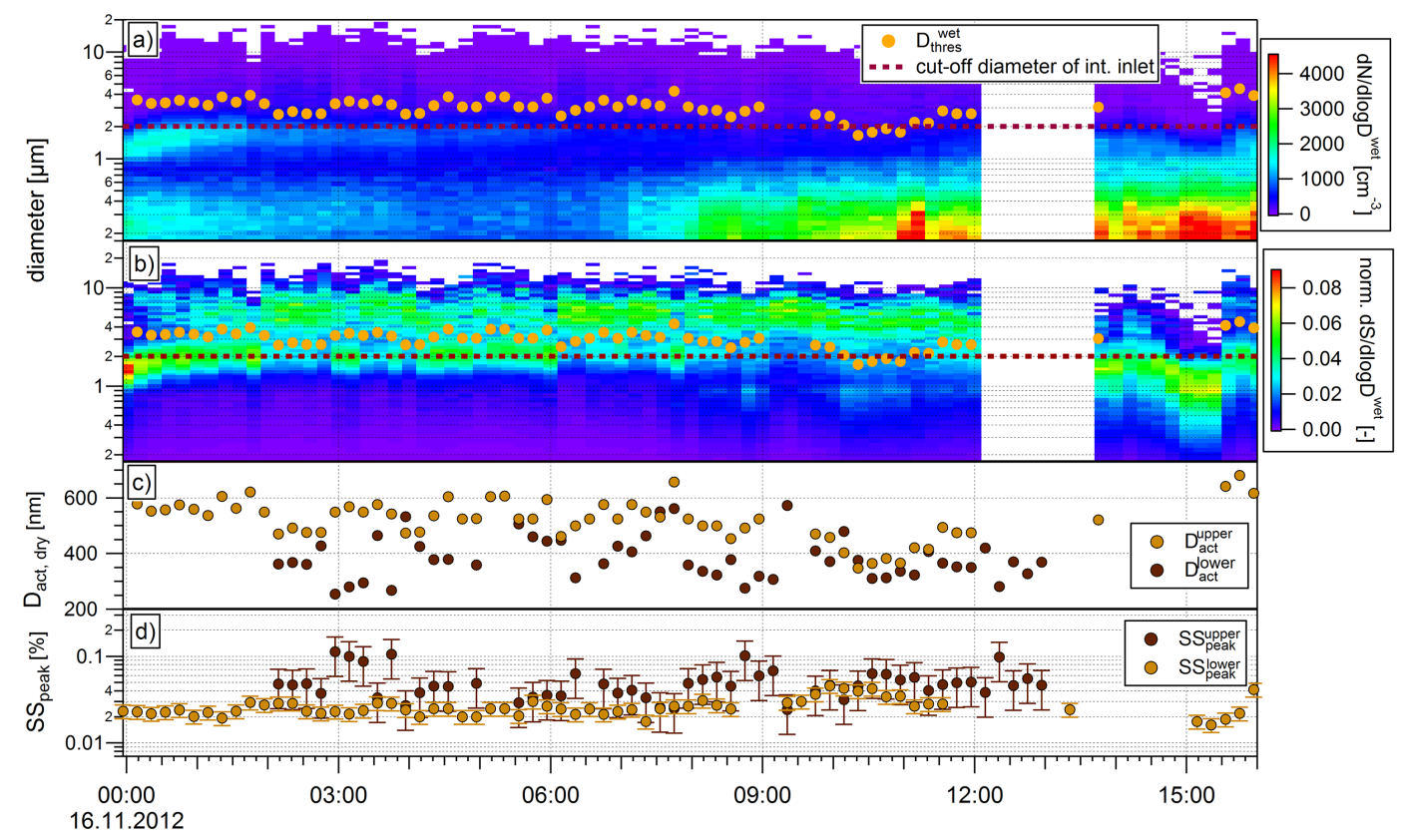

Figure 7. Radiation fog event F11 observed on 16 November 2012. Ambient number size distribution $\left(\frac{\mathrm{d} N}{\operatorname{dlog} D^{\text {wet }}}\right)$ obtained by $\operatorname{combining}$ the WELAS measurement (for $D^{\text {wet }}>1 \mu \mathrm{m}$ ) merged with the SMPS measurement recalculated to RH=100\% (for $D^{\text {wet }}<1 \mu \mathrm{m}$ ) (a), the corresponding normalized ambient surface size distribution $\left(\frac{\mathrm{d} S}{\operatorname{d} \log D^{\text {wet }}}\right)(\mathbf{b})$, the dry activation diameters $\left(D_{\text {act }}\right)$ (c), and the corresponding effective peak supersaturations $\left(\mathrm{SS}_{\text {peak }}\right)(\mathbf{d})$. The error bars for $\mathrm{SS}_{\text {peak }}^{\text {lower }}$ and $\mathrm{SS}_{\text {peak }}^{\text {upper }}$ are explained in Sect. 3.7.

representing the averaged $\mathrm{CCN}$ measurement near activation diameters (see Sect. 3.2 and Fig. 5), was used to infer $\mathrm{SS}_{\text {peak }}$ with Köhler theory. Figure $7 \mathrm{~d}$ shows the lower and upper limit estimates of the effective peak supersaturation, $\mathrm{SS}_{\text {peak }}^{\text {lower }}$ and $\mathrm{SS}_{\text {peak }}^{\text {upper }}$, corresponding to the upper and lower limit estimates of the dry activation diameter, $D_{\text {act }}^{\text {upper }}$ and $D_{\text {act }}^{\text {lower }}$, respectively. The results for the fog event F11 indicate a very low supersaturation in the range of $\sim 0.016$ to $0.113 \%$.

As mentioned above, a rather low $\kappa$ value of 0.14 , as measured at dry diameters $<300 \mathrm{~nm}$, is used to infer $\mathrm{SS}_{\text {peak }}^{\text {lower }}$ from $D_{\text {thres }}^{\text {wet }}$ and $\mathrm{SS}_{\text {peak }}^{\text {upper }}$ from $D_{\text {act }}^{\text {lower }}$. It is possible that particles in the dry diameter range above $300 \mathrm{~nm}$ have somewhat larger $\kappa$ values due to the potential addition of hygroscopic material via fog processing. By assuming a higher $\kappa$ value of, for example, 0.34 instead of 0.14 , the $S_{\text {peak }}^{\text {upper }}$ inferred from the $2 \mu \mathrm{m}$ cut-off measurements would become approximately equal to $\mathrm{SS}_{\text {peak }}^{\text {lower }}$ (which is virtually independent of $\kappa$, see Sect. 3.7). Therefore, using a somewhat larger $\kappa$ value would bring the $\mathrm{SS}_{\text {peak }}^{\text {upper }}$ and $\mathrm{SS}_{\text {peak }}^{\text {lower }}$ (as well as $D_{\text {act }}^{\text {lower }}$ and $D_{\text {act }}^{\text {upper }}$ ) to closer agreement. However, in the interest of providing a conservative estimate of the likely range of the effective peak supersaturation in the fog, the lower $\kappa$ value of 0.14 is used.

An overview of the results for all fog events observed in this study is shown in Fig. 8, where the visibility range (Fig. 8a), was used to identify the periods with developed fog. Figure $8 \mathrm{~b}$ shows the time series of the ambient threshold wet diameter, $D_{\text {thres }}^{\text {wet }}$, separating the unactivated but hy- drated particles and the fog droplets, as determined for all fog events when WELAS data is available. The conditions during the fog droplet formation in the vicinity of the SIRTA site are characterized by considerable variability (see also Table 2). The observed $D_{\text {thres }}^{\text {wet }}$ values shown in Fig. $8 \mathrm{~b}$ vary between 1 and $5 \mu \mathrm{m}$, with a campaign median of $2.6 \mu \mathrm{m}$. Elias et al. (2014) reported an average of $4.0 \pm 1.1 \mu \mathrm{m}$, derived from volume size distributions of developed fogs measured in November 2011. Using the volume size distributions (Elias et al., 2014) instead of surface size distributions (this study) for deriving $D_{\text {thres }}^{\text {wet }}$ results in slightly higher threshold diameters and therefore their result is in good agreement with the values presented in this study.

The upper and lower limit estimates of the dry activation diameter are shown in Fig. 8c and median values for all fog events are provided in Table 2. The lower estimates for the dry activation diameter, $D_{\text {act }}^{\text {lower }}$, are systematically smaller for the fog events F4 to F9, when the $1 \mu \mathrm{m}$ cut-off was applied at the interstitial inlet, compared to the results for fog events F1 to F3 and F11 to F15, obtained with the $2 \mu \mathrm{m}$ cut-off. This difference in $D_{\text {act }}^{\text {lower }}$ between the two subsets is artificial and can be attributed to the larger low bias introduced by the $1 \mu \mathrm{m}$ cut-off. The fact that the upper limit estimates of the dry activation diameter, $D_{\text {act }}^{\text {upper }}$, do not exhibit a systematic difference between the two subsets, excludes a difference in the fog properties as a cause. The true activation diameter 


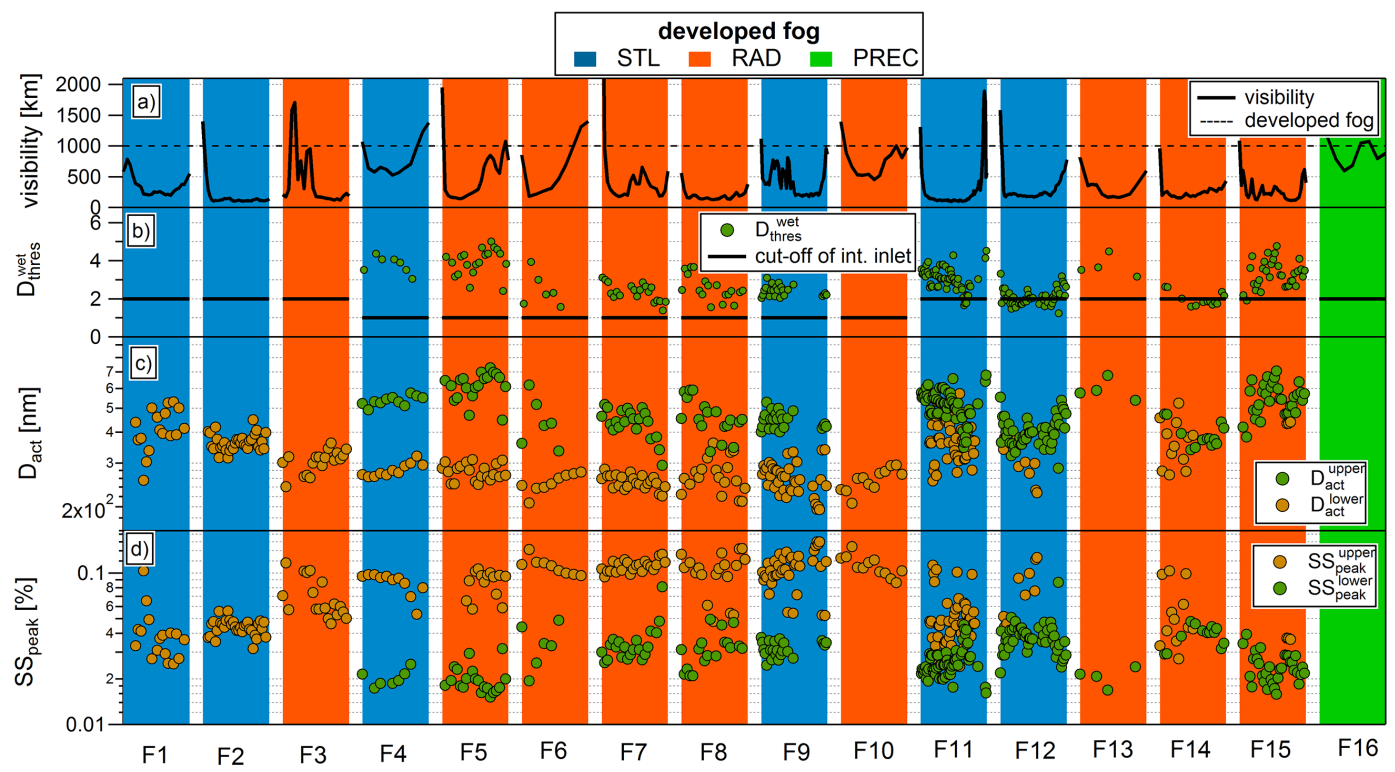

Figure 8. Visibility (a), wet activation threshold diameters (b), dry activation diameters $\left(D_{\text {act }}^{\text {dry }}\right)$ (c), and effective peak supersaturation values $\left(\mathrm{SS}_{\text {peak }}\right)(\mathbf{d})$.

is likely between $D_{\text {act }}^{\text {upper }}$ and $D_{\text {act }}^{\text {lower }}$ from the measurements with the $2 \mu \mathrm{m}$ cut-off.

All fog events feature rather high median $D_{\text {act }}^{\text {lower }}$ and $D_{\text {act }}^{\text {upper }}$, indicating that only a small fraction at the upper end of the particle size distribution is able to activate to fog droplets. The range of dry activation diameters observed in this study overlaps with the range of typical $D_{\text {act }}$ values reported in other fog studies $(\sim 300$ to $\sim 500 \mathrm{~nm}$; e.g., Noone et al., 1992a; Ming and Russell, 2004). However, the dry activation diameters observed in the fog are considerably larger than those observed and/or inferred within stratus or cumulus clouds (e.g., Ditas et al., 2012; Hammer et al., 2014; Hudson and Rogers, 1986; Krüger et al., 2014; McFiggans et al., 2006) due to the lower $S_{\text {peak }}$ encountered in fog.

The effective peak supersaturations determined for all fog events during ParisFog 2012/13 are shown in Fig. 8d. For the upper estimate, the results from events F11-F15 ( $2 \mu \mathrm{m}$ cut-off) are expected to be closer to the true value for the reasons explained above. The effective peak supersaturation is always very low, with limiting values between $0.016 \%$ and $0.113 \%$. Differences in the observed $\mathrm{SS}_{\text {peak }}$ values between different fog events are of similar magnitude as the accuracy. Nevertheless, these differences reflect true differences of the fog properties, as the small point-to-point variability of adjacent data points indicates a relatively high precision. The median effective peak supersaturation falls between $\mathrm{SS}_{\text {peak }}^{\text {lower }} \approx 0.03 \%$ and $\mathrm{SS}_{\text {peak }}^{\text {upper }} \approx 0.05 \%$ (see Table 2 ). The variability of the effective peak supersaturation values is shown in Fig. 9. Half of the data points fall between $0.02 \%$ (25th percentile of $\mathrm{SS}_{\text {peak }}^{\text {lower }} ; 2 \mu \mathrm{m}$ data only) and $0.06 \%$ (75th percentile of $\mathrm{SS}_{\text {peak }}^{\text {upper }}$, while the respective 10th and 90th per-

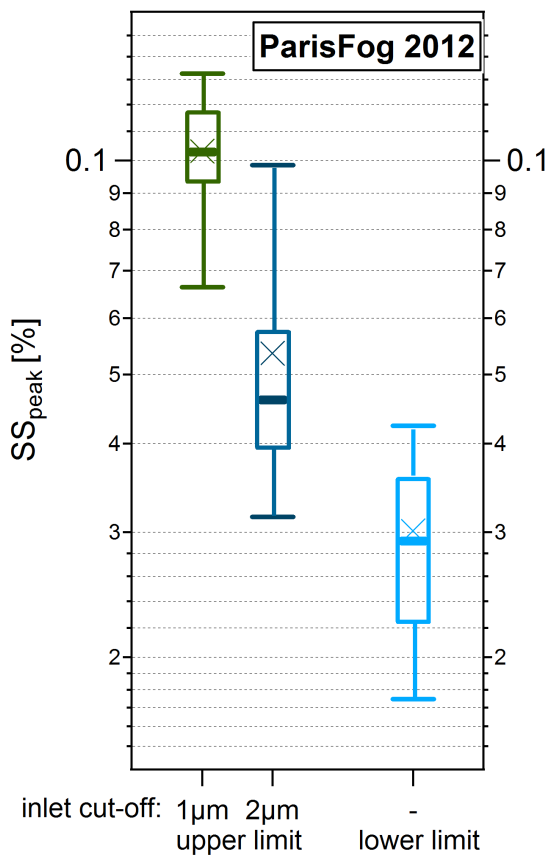

Figure 9. 10th, 25th, 50th (median), 75th and 90th percentiles (box plot) and mean value (cross) of the effective peak supersaturation $\left(\mathrm{SS}_{\text {peak }}\right)$ for the upper and lower estimate for ParisFog 2012/13. For the upper estimate, the data was split according to the cut-off diameter at the interstitial inlet, $1 \mu \mathrm{m}\left(\mathrm{PM}_{1}\right)$ and $2 \mu \mathrm{m}\left(\mathrm{PM}_{2}\right)$. 
centile values are $0.017 \%$ and $0.1 \%$. These values, observed during ParisFog 2012/2013, are within the range of previous literature reports of measured and modeled peak supersaturations in fog $\left(\mathrm{SS}_{\text {peak }}<\sim 0.1 \%\right.$; e.g., Meng and Seinfeld, 1994; Pandis and Seinfeld, 1989).

\subsubsection{Effect of local emissions on fog properties}

The results shown in Fig. 4 show a higher particle number concentration while wind directions from the Paris city center were measured (sector between $\sim 0$ and $\sim 90^{\circ}$ ). However, neither the obtained $\mathrm{SS}_{\text {peak }}$ nor the $\kappa$ values show any dependence on the wind direction. Laborde et al. (2013) showed, through the combined analysis of aerosol composition and hygroscopicity distribution data measured at the SIRTA site in winter 2010, that a dominant number fraction of the particles with a diameter of $110 \mathrm{~nm}$ often originates from local emissions from within Paris, while the dominant fraction of the particles with a diameter of $265 \mathrm{~nm}$ can be attributed to the background aerosol. This size dependence of local influence can be explained by the fact that the size distribution of primary particle emissions from combustion sources peaks at rather small sizes clearly below the maximum of the background aerosol size distribution. The observations of this study showed that only particles with dry diameters larger than $300-500 \mathrm{~nm}$ are able to act as condensation nuclei for fog droplets due to the low peak supersaturation. This finding is consistent with the small number concentration of fog droplets usually measured at the SIRTA site (Elias et al., 2014). Therefore, the local emissions composed of small particles do not have a substantial effect on the resulting fog droplet number concentration. The fact that the freshly emitted particles are less hygroscopic than the background aerosol (Laborde et al., 2013), which shifts the activation threshold diameter for local emissions even higher up, further amplifies the dominant influence of background aerosol particles. Crippa et al. (2013a) showed, by parallel measurements of fine particulate matter (PM1) at three measurement sites across Paris in winter 2010, that variations of aerosol mass concentration and composition are dominated by regional-scale influence, while local emissions only give a minor contribution. This is consistent with the abovementioned findings from Laborde et al. (2013), given the fact that the dominant contribution to particle mass and bulk composition comes from larger particles, which are mainly from the background aerosol. The regional scale emission may potentially have some influence on fog properties, for example by growing background aerosol mode particles across the activation threshold dry diameter through condensation of secondary aerosol matter. However, this potential effect cannot be quantified from the data set available here.

\subsubsection{Possible influences of in-fog processes on measured $D_{\text {act }}$ and inferred $\mathrm{SS}_{\text {peak }}$}

The size distributions of the total, interstitial and droplet residual particles may be altered by in-fog processes such as fog droplet sedimentation, entrainment of subsaturated air, in-cloud scavenging of interstitial particles, coalescence of fog droplets, and droplet processing, which includes condensation of semi-volatile aerosol components or aqueous phase heterogeneous formation of secondary aerosol within the droplet (e.g., Noone et al., 1992a; Henning et al., 2014). These processes can potentially lead to a bias in the measured $D_{\text {act }}$ compared with the true dry activation diameter at the time of fog formation. A detailed sensitivity analysis, provided in the Supplement, revealed that the measured $D_{\text {act }}$ may be larger (more likely) or smaller (less likely) compared to the true $D_{\text {act }}$ due to the effects of in-fog processes. These artefacts are most likely smaller than $\sim 15 \%$, which is within the specified uncertainty of the measured $D_{\text {act }}$.

\subsection{Contribution of hydrated particles and fog droplets to light scattering}

Visibility is dramatically reduced during the presence of fog. It can decrease from a few kilometers to a few meters within minutes (as occurred for example on 30 November 2012, F15). However, it was observed that only a few of the larger particles are usually able to activate to fog droplets (10 to $150 \mathrm{~cm}^{-3}$; Burnet et al., 2012; Elias et al., 2014).

Elias et al. (2014) showed for earlier campaigns at the same site that hydrated aerosols have a non-negligible contribution to visibility reduction during fog events (500 to $3500 \mathrm{Mm}^{-1}$ ). In order to assess the contributions of the hydrated and activated aerosol to the light scattering, they computed the light scattering coefficient $b_{\mathrm{s}}$, as described in Sect. 3.4. For comparison, Fig. 10 shows the median $b_{\mathrm{s}}$ size distribution measured by the WELAS instrument and retrieved from the estimated wet size distribution from the SMPS instrument for the present study. Table 2 presents the light scattering coefficient of the hydrated aerosol mode $\left(b_{\mathrm{s}, \text { hyd }}\right)$ :

$b_{\mathrm{s}, \text { hyd }}=\int_{D_{\min }}^{D_{\text {thres }}^{\text {wet }}} \frac{\mathrm{d} b_{\mathrm{s}}}{\operatorname{dlog} D^{\text {wet }}} \mathrm{d} \log D^{\text {wet }}$

and the light scattering coefficient of the droplet mode $\left(b_{\mathrm{s}, \mathrm{drop}}\right)$ :

$b_{\mathrm{s}, \text { drop }}=\int_{D_{\text {thres }}^{\text {wet }}}^{D_{\max }} \frac{\mathrm{d} b_{\mathrm{s}}}{\operatorname{dlog} D^{\text {wet }}} \mathrm{d} \log D^{\text {wet }}$.

$D_{\min }$ and $D_{\max }$ are the smallest and largest particle diameters at ambient $\mathrm{RH}$, respectively, that are covered by the 


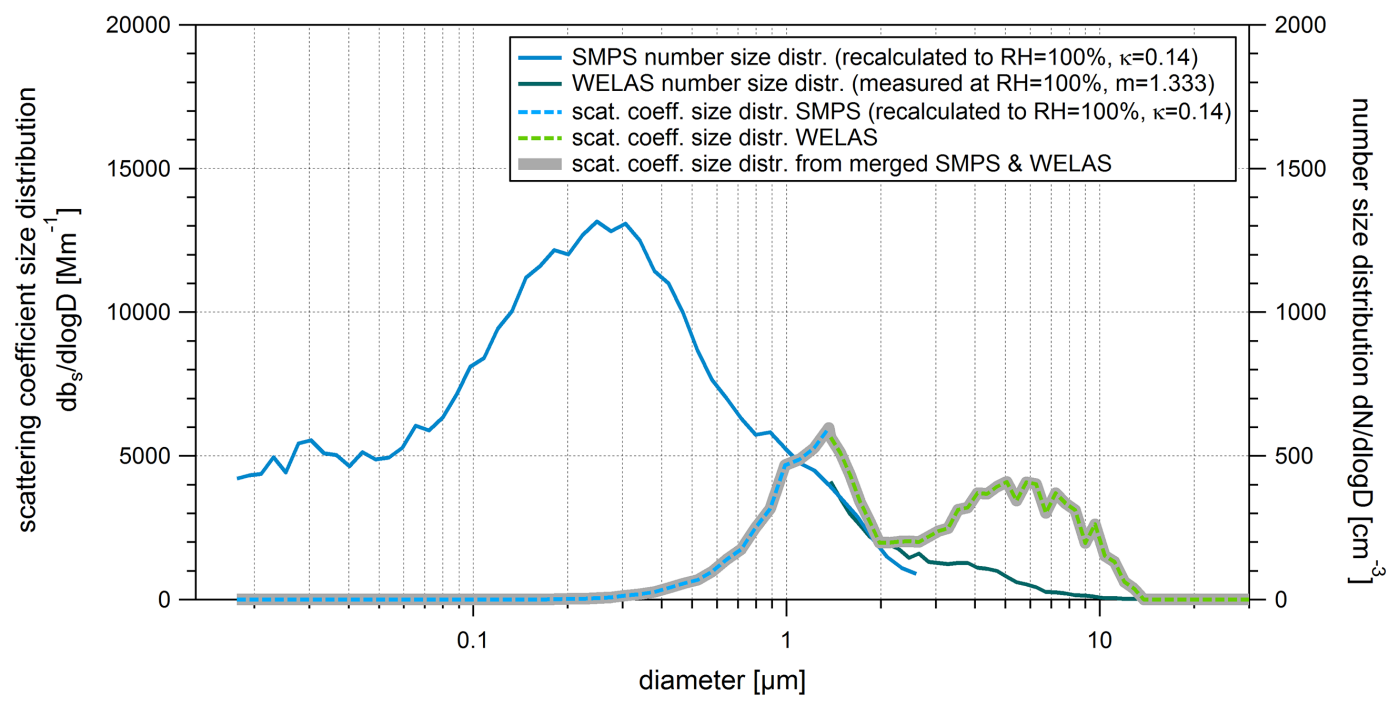

Figure 10. For the fog event F9 on 12 November 2012: median (bin-wise) aerosol number size distribution at ambient RH from recalculated SMPS and WELAS measurements. The scattering coefficient size distribution was obtained by calculating the bin-wise median of the individual normalized size distributions, followed by scaling with the median of the individual total scattering coefficient values $\left(b_{\mathrm{s}, \text { tot }}\right.$; obtained by integrating the individual scattering coefficient size distributions).

SMPS and WELAS measurements. Additionally, in Table 2 the fractional contribution, $\frac{b_{\mathrm{s}, \text { hyd }}}{\left(b_{\mathrm{s}, \text { drop }}+b_{\mathrm{s}, \text { hyd }}\right)}$, of the hydrated particles mode to the total light scattering coefficient of all particles and droplets is reported. This fraction ranges from 41 up to $93 \%$ with a median of $68 \%$ (see Table 2). The studies of Burnet et al. (2012) and Elias et al. (2014) showed that WELAS measurements alone are not able to reproduce the light scattering of the larger fog droplets (only droplets up to a size range of $\sim 10 \mu \mathrm{m}$ can be detected with a WELAS). In order to obtain an estimate of the total light scattering of all particles, including all fog droplets, the WELAS data would need to be complemented with a fog droplet probe. Another method is to calculate the particle extinction coefficient (pec) from the visibilimeter data using the Koschmieder equation (Koschmieder, 1925; Harrison, 2012) as has been done in Elias et al. (2009):

pec $=\frac{-\ln \left(C_{\mathrm{v}}\right)}{\text { visibility }}$.

$C_{\mathrm{V}}$ is the visual contrast, which is defined at $5 \%$ for the visibilimeter. The pec is retrieved for a halogen lamp spectrum (in the wavelength range $350-900 \mathrm{~nm}$ peaking at $550 \mathrm{~nm}$; spectrum used from www.uvguide.co.uk (last access: 6 November 2013), which is similar to the visible part of the solar spectrum) and is listed in Table 2. During most of the fog events the pec values are higher than $\left(b_{\mathrm{s} \text {, hyd }}+b_{\mathrm{s}, \mathrm{drop}}\right)$, which can to some extent be attributed to the undetected largest fog droplets. For comparison, the ratio of $\frac{b_{\mathrm{s}, \text { hyd }}}{\text { pec }}$ is also presented in Table 2. A mean value of 0.41 is observed for $\frac{b_{\text {s,hyd }}}{\text { pec }}$, which is somewhat lower than the mean value (0.68) of $\frac{b_{\mathrm{s}, \text { hyd }}}{b_{\mathrm{s}, \text { drop }}+b_{\mathrm{s}, \text { hyd }}}$. This can be attributed to experimental un- certainty and the fact that the WELAS is undercounting the largest activated droplets with $D>10 \mu \mathrm{m}$, thereby resulting in a low bias of $b_{\mathrm{s} \text {, drop }}$ and a high bias of $\frac{b_{\mathrm{s} \text {, hyd }}}{b_{\mathrm{s}, \text { drop }}+b_{\mathrm{s} \text {, hyd }}}$, when large droplets are present. Nevertheless, the conclusion that the hydrated but non-activated particles give a significant contribution to the visibility reduction also remains valid when considering the ratio $\frac{b_{\mathrm{s} \text {, hyd }}}{\text { pec }}$.

\section{Conclusions}

During the ParisFog 2012/13 field campaign, performed at the semi-urban site SIRTA in Palaiseau, close to Paris, 17 developed fog events were observed and examined regarding their aerosol-to-fog droplet activation properties. Aerosol and droplet size distributions were obtained at ambient relative humidity. The activated fraction of the particles was acquired using total and interstitial particle dry size distribution measurements. $\mathrm{CCN}$ number concentrations were measured at different SS to obtain particle hygroscopicity.

The hygroscopicity parameter, $\kappa$, was calculated for the whole campaign and values (in the range of measured particle diameters) were found between 0.06 and 0.27 , and centered at 0.14 . These values are in the same range as observed in earlier studies at SIRTA and Paris city center. These rather low values likely indicate substantial influence of road traffic and wood burning emissions.

Two alternative approaches were applied to investigate the fog droplet activation process. The wet activation threshold diameter, separating the activated fog droplets from the non-activated but hydrated particles, was found to be around $2.6 \mu \mathrm{m}$. The median dry activation diameter was estimated 
to lie between 364 and $450 \mathrm{~nm}$. This implies a median peak supersaturation between 0.03 and $0.05 \%$ for ParisFog $2012 / 2013$, which is in good agreement with literature values.

The hydrated particles were estimated to contribute on average $\sim 41-68 \%$ to total light-scattering during the developed fog periods. This study revealed a very weak separation between the activated fog droplets and the non-activated but hydrated particles. This makes it difficult to use an interstitial inlet for separating the non-activated particles from the activated fog droplets. Thus, great care has to be taken to choose the ideal inlet cut-off, possibly variable in time, in order to avoid or minimize biases that can be introduced by removing too many small or too few large particles in the inlet, if the cut-off falls into one of the two modes rather than in between them.

\section{The Supplement related to this article is available online at doi:10.5194/acp-14-10517-2014-supplement.}

Acknowledgements. We would like to thank the SIRTA team who helped us during the campaign with the maintenance and establishment of the measurements. We would like to thank B. Rosati for fruitful discussions concerning the WELAS measurements and her help with the Mie calculations. The research leading to these results has received funding from the EU/FP7 ACTRIS transnational access to the SIRTA Atmospheric Observatory and the European Union Seventh Framework Programme (FP7/2007-2013) under grant agreement no. 262254. CRH was funded by SNF grant no. 200021 140663. MG was funded by ERC-2013-CoG 615922-BLACARAT. PVM and WELAS instruments are set up at SIRTA thanks to the PreViBOSS project (in collaboration with CNRS-HYGEOS) funded by DGA/DGCIS.

Edited by: V.-M. Kerminen

\section{References}

Allan, J. D., Baumgardner, D., Raga, G. B., Mayol-Bracero, O. L., Morales-García, F., García-García, F., Montero-Martínez, G., Borrmann, S., Schneider, J., Mertes, S., Walter, S., Gysel, M., Dusek, U., Frank, G. P., and Krämer, M.: Clouds and aerosols in Puerto Rico - a new evaluation, Atmos. Chem. Phys., 8, 12931309, doi:10.5194/acp-8-1293-2008, 2008.

Andreae, M. O. and Rosenfeld, D.: Aerosol-cloudprecipitation interactions, Part 1 . The nature and sources of cloud-active aerosols, Earth-Sci. Rev., 89, 13-41, doi:10.1016/j.earscirev.2008.03.001, 2008.

Baltensperger, U., Streit, N., Weingartner, E., Nyeki, S., Prévôt, A. S. H., Van Dingenen, R., Virkkula, A., Putaud, J.-P., Even, A., ten Brink, H., Blatter, A., Neftel, A., and Gäggeler, H. W.: Urban and rural aerosol characterization of summer smog events during the PIPAPO field campaign in Milan, Italy, J. Geophys. Res.-Atmos., 107, 8193, doi:10.1029/2001JD001292, 2002.
Bergot, T.: Quality assessment of the Cobel-Isba numerical forecast system of fog and low clouds, Pure Appl. Geophys., 164, 12651282, doi:10.1007/s00024-007-0218-3, 2007.

Bott, A., Sievers, U., and Zdunkowski, W.: A radiation fog model with a detailed treatment of the interaction between radiativetransfer and fog microphysics, J. Atmos. Sci., 47, 2153-2166, doi:10.1175/1520-0469(1990)047<2153:ARFMWA>2.0.CO;2, 1990.

Burnet, F., Gomes, L., Haeffelin, M., Dupont, J., and Elias, T.: Analysis of the microphysical structures of fog during the ParisFog project, in: Proceedings of the 16th international conference of clouds and precipitation (ICCP), Leipzig, Germany, 30 July-3 August, 582, 2012.

Crippa, M., DeCarlo, P. F., Slowik, J. G., Mohr, C., Heringa, M. F., Chirico, R., Poulain, L., Freutel, F., Sciare, J., Cozic, J., Di Marco, C. F., Elsasser, M., Nicolas, J. B., Marchand, N., Abidi, E., Wiedensohler, A., Drewnick, F., Schneider, J., Borrmann, S., Nemitz, E., Zimmermann, R., Jaffrezo, J.-L., Prévôt, A. S. H., and Baltensperger, U.: Wintertime aerosol chemical composition and source apportionment of the organic fraction in the metropolitan area of Paris, Atmos. Chem. Phys., 13, 961-981, doi:10.5194/acp-13-961-2013, 2013a.

Crippa, M., El Haddad, I., Slowik, J. G., DeCarlo, P. F., Mohr, C., Heringa, M. F., Chirico, R., Marchand, N., Sciare, J., Baltensperger, U., and Prevot, A. S. H.: Identification of marine and continental aerosol sources in Paris using high resolution aerosol mass spectrometry, J. Geophys. Res.-Atmos., 118, 1950-1963, doi:10.1002/jgrd.50151, $2013 \mathrm{~b}$.

David, N., Alpert, P., and Messer, H.: The potential of cellular network infrastructures for sudden rainfall monitoring in dry climate regions, Atmos. Res., 131, 13-21, doi:10.1016/j.atmosres.2013.01.004, 2013.

Ditas, F., Shaw, R. A., Siebert, H., Simmel, M., Wehner, B., and Wiedensohler, A.: Aerosols-cloud microphysicsthermodynamics-turbulence: evaluating supersaturation in a marine stratocumulus cloud, Atmos. Chem. Phys., 12, 2459-2468, doi:10.5194/acp-12-2459-2012, 2012.

Dupont, J.-C., Haeffelin, M., Protat, A., Bouniol, D., Boyouk, N., and Morille, Y.: Stratus - fog formation and dissipation: a 6-day case study, Bound.-Lay. Meteorol., 143, 207-225, doi:10.1007/s10546-012-9699-4, 2012.

Duynkerke, P. G.: Radiation fog: a comparison of model simulation with detailed observations, Mon. Weather Rev., 119, 324-341, doi:10.1175/1520-0493(1991)119<0324:RFACOM>2.0.CO;2, 1991.

Elias, T., Haeffelin, M., Drobinski, P., Gomes, L., Rangognio, J., Bergot, T., Chazette, P., Raut, J.-C., and Colomb, M.: Particulate contribution to extinction of visible radiation: pollution, haze, and fog, Atmos. Res., 92, 443-454, doi:10.1016/j.atmosres.2009.01.006, 2009.

Elias, T., Dupont, J.-C., Hammer, E., Hoyle, C. R., Haeffelin, M., Burnet, F., and Jolivet, D.: Enhanced extinction of visible radiation due to hydrated aerosols in mist and fog, Atmos. Chem. Phys., submitted, 2014.

Facchini, M. C., Fuzzi, S., Lind, J. A., Fierlinger-Oberlinninger, H., Kalina, M., Puxbaum, H., Winiwarter, W., Arends, B. G., Wobrock, W., Jaeschke, W., Berner, A., and Kruisz, C.: Phase-partitioning and chemical reactions of low molecular 
weight organic compounds in fog, Tellus B, 44, 533-544, doi:10.1034/j.1600-0889.1992.t01-3-00007.x, 1992.

Fuzzi, S., Facchini, M. C., Orsi, G., and Ferri, D.: Seasonal trend of fog water chemical composition in the Po Valley, Environ. Pollut., 75, 75-80, doi:10.1016/0269-7491(92)90059-J, 1992.

Gerber, H.: Supersaturation and droplet spectral evolution in fog, J. Atmos. Sci., 48, 2569-2588, doi:10.1175/15200469(1991)048<2569:Sadsei>2.0.Co;2, 1991.

Guedalia, D. and Bergot, T.: Numerical forecasting of radiation fog, Part II: A comparison of model simulation with several observed fog events, Mon. Weather Rev., 122, 1231-1246, doi:10.1175/1520-0493(1994)122<1231:NFORFP>2.0.CO;2, 1994.

Gultepe, I., Tardif, R., Michaelides, S. C., Cermak, J., Bott, A., Bendix, J., Müller, M. D., Pagowski, M., Hansen, B., Ellrod, G., Jacobs, W., Toth, G., and Cober, S. G.: Fog research: a review of past achievements and future perspectives, Pure Appl. Geophys., 164, 1121-1159, doi:10.1007/s00024-007-0211-x, 2007.

Haeffelin, M., Barthès, L., Bock, O., Boitel, C., Bony, S., Bouniol, D., Chepfer, H., Chiriaco, M., Cuesta, J., Delanoë, J., Drobinski, P., Dufresne, J.-L., Flamant, C., Grall, M., Hodzic, A., Hourdin, F., Lapouge, F., Lemaître, Y., Mathieu, A., Morille, Y., Naud, C., Noël, V., O'Hirok, W., Pelon, J., Pietras, C., Protat, A., Romand, B., Scialom, G., and Vautard, R.: SIRTA, a ground-based atmospheric observatory for cloud and aerosol research, Ann. Geophys., 23, 253-275, doi:10.5194/angeo-23-253-2005, 2005.

Haeffelin, M., Bergot, T., Elias, T., Tardif, R., Carrer, D., Chazette, P., Colomb, M., Drobinski, P., Dupont, E., Dupont, J. C., Gomes, L., Musson-Genon, L., Pietras, C., Plana-Fattori, A., Protat, A., Rangognio, J., Raut, J. C., Remy, S., Richard, D., Sciare, J., and Zhang, X.: Parisfog shedding new light on fog physical processes, B. Am. Meteorol. Soc., 91, 767-783, doi:10.1175/2009BAMS2671.1, 2010.

Haeffelin, M., Dupont, J.-C., Boyouk, N., Baumgardner, D., Gomes, L., Roberts, G., and Elias, T.: A comparative study of radiation fog and quasi-fog formation processes during the ParisFog field experiment 2007, Pure Appl. Geophys., 170, 22832303, doi:10.1007/s00024-013-0672-z, 2013.

Hammer, E., Bukowiecki, N., Gysel, M., Jurányi, Z., Hoyle, C. R., Vogt, R., Baltensperger, U., and Weingartner, E.: Investigation of the effective peak supersaturation for liquid-phase clouds at the high-alpine site Jungfraujoch, Switzerland (3580 m a.s.1.), Atmos. Chem. Phys., 14, 1123-1139, doi:10.5194/acp-14-11232014, 2014.

Harrison, R.: Aerosol-induced correlation between visibility and atmospheric electricity, J. Aerosol Sci., 52, 121-126, doi:10.1016/j.jaerosci.2012.04.011, 2012.

Heim, M., Mullins, B. J., Umhauer, H., and Kasper, G.: Performance evaluation of three optical particle counters with an efficient "multimodal" calibration method, J. Aerosol Sci., 39, 1019-1031, doi:10.1016/j.jaerosci.2008.07.006, 2008.

Heintzenberg, J.: The Po Valley Fog Experiment 1989 - what have we learned, where do we go from here?, Tellus B, 44, 443-447, doi:10.1034/j.1600-0889.1991.t01-3-00002.x-i1, 1992.

Henning, S., Weingartner, E., Schmidt, S., Wendisch, M., Gaggeler, H. W., and Baltensperger, U.: Size-dependent aerosol activation at the high-alpine site Jungfraujoch (3580 ma.s.l.), Tellus B, 54, 82-95, doi:10.1034/j.1600-0889.2002.00299.x, 2002.
Henning, S., Dieckmann, K., Ignatius, K., Schäfer, M., Zedler, P., Harris, E., Sinha, B., van Pinxteren, D., Mertes, S., Birmili, W., Merkel, M., Wu, Z., Wiedensohler, A., Wex, H., Herrmann, H., and Stratmann, F.: Influence of cloud processing on CCN activation behaviour in the Thuringian Forest, Germany during HCCT2010, Atmos. Chem. Phys., 14, 7859-7868, doi:10.5194/acp-147859-2014, 2014.

Hudson, J. G. and Rogers, C. F.: Relationship between critical supersaturation and cloud droplet size: implications for cloud mixing processes, J. Atmos. Sci., 43, 2341-2359, doi:10.1175/15200469(1986)043<2341:RBCSAC>2.0.CO;2, 1986.

Hupfer, P., Kuttler, W., and Chmielewski, F.-M.: Witterung und Klima: eine Einführung in die Meteorologie und Klimatologie, Springer, Germany, 2005.

Jurányi, Z., Gysel, M., Weingartner, E., Bukowiecki, N., Kammermann, L., and Baltensperger, U.: A 17 month climatology of the cloud condensation nuclei number concentration at the high alpine site Jungfraujoch, J. Geophys. Res.-Atmos., 116, D10204, doi:10.1029/2010JD015199, 2011.

Jurányi, Z., Tritscher, T., Gysel, M., Laborde, M., Gomes, L., Roberts, G., Baltensperger, U., and Weingartner, E.: Hygroscopic mixing state of urban aerosol derived from sizeresolved cloud condensation nuclei measurements during the MEGAPOLI campaign in Paris, Atmos. Chem. Phys., 13, 64316446, doi:10.5194/acp-13-6431-2013, 2013.

Kamilli, K. A., Poulain, L., Held, A., Nowak, A., Birmili, W., and Wiedensohler, A.: Hygroscopic properties of the Paris urban aerosol in relation to its chemical composition, Atmos. Chem. Phys., 14, 737-749, doi:10.5194/acp-14-737-2014, 2014.

Kim, C. and Yum, S.: A numerical study of sea-fog formation over cold sea surface using a one-dimensional turbulence model coupled with the weather research and forecasting model, Bound.Lay. Meteorol., 143, 481-505, doi:10.1007/s10546-012-9706-9, 2012.

Köhler, H.: The nucleus in and the growth of hygroscopic droplets, T. Faraday Soc., 32, 1152-1161, 1936.

Koschmieder, H.: Theorie der horizontalen Sichtweite, Beiträge Physicae Freiberger Atmosphere, 12, 171-181, 1925.

Krüger, M. L., Mertes, S., Klimach, T., Cheng, Y. F., Su, H., Schneider, J., Andreae, M. O., Pöschl, U., and Rose, D.: Assessment of cloud supersaturation by size-resolved aerosol particle and cloud condensation nuclei (CCN) measurements, Atmos. Meas. Tech., 7, 2615-2629, doi:10.5194/amt-7-2615-2014, 2014.

Laborde, M., Crippa, M., Tritscher, T., Jurányi, Z., Decarlo, P. F., Temime-Roussel, B., Marchand, N., Eckhardt, S., Stohl, A., Baltensperger, U., Prévôt, A. S. H., Weingartner, E., and Gysel, M.: Black carbon physical properties and mixing state in the European megacity Paris, Atmos. Chem. Phys., 13, 5831-5856, doi:10.5194/acp-13-5831-2013, 2013.

Maier, F., Bendix, J., and Thies, B.: Development and application of a method for the objective differentiation of fog life cycle phases, Tellus B, 65, 19971, doi:10.3402/tellusb.v65i0.19971, 2013.

McFiggans, G., Artaxo, P., Baltensperger, U., Coe, H., Facchini, M. C., Feingold, G., Fuzzi, S., Gysel, M., Laaksonen, A., Lohmann, U., Mentel, T. F., Murphy, D. M., O’Dowd, C. D., Snider, J. R., and Weingartner, E.: The effect of physical and chemical aerosol properties on warm cloud droplet activation, Atmos. Chem. Phys., 6, 2593-2649, doi:10.5194/acp-6-2593-2006, 2006. 
Meng, Z. and Seinfeld, J. H.: On the source of the submicrometer droplet mode of urban and regional aerosols, Aerosol Sci. Tech., 20, 253-265, doi:10.1080/02786829408959681, 1994.

Meyer, M. B., Lala, G. G., and Jiusto, J. E.: Fog-82: a cooperative field study of radiation fog, B. Am. Meteorol. Soc., 67, 825-832, doi:10.1175/1520-0477(1986)067<0825:FACFSO>2.0.CO;2, 1986.

Ming, Y. and Russell, L. M.: Organic aerosol effects on fog droplet spectra, J. Geophys. Res.-Atmos., 109, D10109, doi:10.1029/2003JD004427, 2004.

Nenes, A., Ghan, S., Abdul-Razzak, H., Chuang, P. Y., and Seinfeld, J. H.: Kinetic limitations on cloud droplet formation and impact on cloud albedo, Tellus B, 53, 133-149, doi:10.1034/j.16000889.2001.d01-12.x, 2001.

Noone, K. J., Ogren, J. A., Hallberg, A., Hansson, H. C., Wiedensohler, A., and Swietlicki, E.: A statistical examination of the chemical differences between interstitial and scavenged aerosol, Tellus B, 44, 581-592, doi:10.1034/j.1600-0889.1992.t01-100011.x, 1992a.

Noone, K. J., Ogren, J. A., Hallberg, A., Heintzenberg, J., Strom, J., Hansson, H. C., Svenningsson, B., Wiedensohler, A., Fuzzi, S., Facchini, M. C., Arends, B. G., and Berner, A.: Changes in aerosol size and phase distributions due to physical and chemical processes in fog, Tellus B, 44, 489-504, doi:10.1034/j.16000889.1992.t01-4-00004.x, 1992b.

Pandis, S. N. and Seinfeld, J. H.: Mathematical-modeling of acid deposition due to radiation fog, J. Geophys. Res.-Atmos., 94, 12911-12923, doi:10.1029/JD094iD10p12911, 1989.

Petters, M. D. and Kreidenweis, S. M.: A single parameter representation of hygroscopic growth and cloud condensation nucleus activity, Atmos. Chem. Phys., 7, 1961-1971, doi:10.5194/acp-71961-2007, 2007.

Phinney, L. A., Lohmann, U., and Leaitch, R.: Limitations of using an equilibrium approximation in an aerosol activation parameterization, J. Geophys. Res., 108, 4371, doi:10.1029/2002JD002391, 2003.

Pringle, K. J., Tost, H., Pozzer, A., Pöschl, U., and Lelieveld, J.: Global distribution of the effective aerosol hygroscopicity parameter for $\mathrm{CCN}$ activation, Atmos. Chem. Phys., 10, 52415255, doi:10.5194/acp-10-5241-2010, 2010.

Roberts, G. C. and Nenes, A.: A continuous-flow streamwise thermal-gradient $\mathrm{CCN}$ chamber for atmospheric measurements, Aerosol Sci. Tech., 39, 206-221, doi:10.1080/027868290913988, 2005.

Rosati, B., Wehrle, G., Zieger, P., Gysel, M., Baltensperger, U., and Weingartner, E.: The white-light humidified optical particle spectrometer (WHOPS) - a novel airborne system to characterize aerosol hygroscopicity, Atmos. Meas. Tech. Discuss., 7, 73217366, doi:10.5194/amtd-7-7321-2014, 2014.
Rosenfeld, J.: Cars vs. the weather: a century of progress, Weatherwise, 49, 14-23, doi:10.1080/00431672.1996.9925430, 1996.

Stolaki, S., Pytharoulis, I., and Karacostas, T.: A study of fog characteristics using a coupled WRF-COBEL model over Thessaloniki airport, Greece, Pure Appl. Geophys., 169, 961-981, doi:10.1007/s00024-011-0393-0, 2012.

Sullivan, R. C., Moore, M. J. K., Petters, M. D., Kreidenweis, S. M., Roberts, G. C., and Prather, K. A.: Effect of chemical mixing state on the hygroscopicity and cloud nucleation properties of calcium mineral dust particles, Atmos. Chem. Phys., 9, 33033316, doi:10.5194/acp-9-3303-2009, 2009.

Svenningsson, I. B., Hansson, H. C., Wiedensohler, A., Ogren, J. A., Noone, K. J., and Hallberg, A.: Hygroscopic growth of aerosol-particles in the Po Valley, Tellus B, 44, 556-569, doi:10.1034/j.1600-0889.1992.t01-1-00009.x, 1992.

Tardif, R. and Rasmussen, R. M.: Event-based climatology and typology of fog in the New York City region, J. Appl. Meteorol. Clim., 46, 1141-1168, doi:10.1175/JAM2516.1, 2007.

Vautard, R., Yiou, P., and van Oldenborgh, G. J.: Decline of fog, mist and haze in Europe over the past 30 years, Nat. Geosci., 2, 115-119, doi:10.1038/ngeo414, 2009.

Verheggen, B., Cozic, J., Weingartner, E., Bower, K., Mertes, S., Connolly, P., Gallagher, M., Flynn, M., Choularton, T., and Baltensperger, U.: Aerosol partitioning between the interstitial and the condensed phase in mixed-phase clouds, J. Geophys. Res. Atmos., 112, D23202, doi:10.1029/2007JD008714, 2007.

Wiedensohler, A., Birmili, W., Nowak, A., Sonntag, A., Weinhold, K., Merkel, M., Wehner, B., Tuch, T., Pfeifer, S., Fiebig, M., Fjäraa, A. M., Asmi, E., Sellegri, K., Depuy, R., Venzac, H., Villani, P., Laj, P., Aalto, P., Ogren, J. A., Swietlicki, E., Williams, P., Roldin, P., Quincey, P., Hüglin, C., Fierz-Schmidhauser, R., Gysel, M., Weingartner, E., Riccobono, F., Santos, S., Grüning, C., Faloon, K., Beddows, D., Harrison, R., Monahan, C., Jennings, S. G., O’Dowd, C. D., Marinoni, A., Horn, H.-G., Keck, L., Jiang, J., Scheckman, J., McMurry, P. H., Deng, Z., Zhao, C. S., Moerman, M., Henzing, B., de Leeuw, G., Löschau, G., and Bastian, S.: Mobility particle size spectrometers: harmonization of technical standards and data structure to facilitate high quality long-term observations of atmospheric particle number size distributions, Atmos. Meas. Tech., 5, 657-685, doi:10.5194/amt5-657-2012, 2012.

Zhao, C. F., Klein, S. A., Xie, S. C., Liu, X. H., Boyle, J. S., and Zhang, Y. Y.: Aerosol first indirect effects on nonprecipitating low-level liquid cloud properties as simulated by CAM5 at ARM sites, Geophys. Res. Lett., 39, 1944-8007, doi:10.1029/2012g1051213, 2012. 